\title{
Sobre el ministerio eclesial (II)
}

\section{La clericalización del ministerio}

\section{José Ignacio González Faus, Facultad de Teología de Cataluña, Centro de Reflexión Teológica, San Salvador.}

La evolución que vamos a trazar recoge, sobre todo, aquella línea que, de hecho, logró cuajar e imponerse. En la práctica, esa línea (que, como tal, sólo es deteclable desde el hoy) cohabita con otros mil intentos, a derecha 0 a izquierda, que no acabaron de cuajar. Así por ejemplo, la carı de Plinio el Joven a Trajano (hacia el año 112) habla de que ha "torturado a unas esclavas a quienes ellos [los cristianos] llaman diaconisas." Las Constifuciones Apostólicas (hacia el 380), en su capílulo VII, parecen introducir a la mujer en la jerarqufa; pero, pese al gran influjo que tuvieron, acabaron siendo condenadas en el siglo VII. También la Didaskalia (hacia el 230) refleja una Iglesia más organizada y clericalizada de lo que habian sido las iglesias de los siglos I y II; en cambio, la estructura que describe no es la que se impuso en la historia ( $c f$. II, 26,3-8, donde asimila la figura del obispo al Padre, la del diácono a Cristo, y la de la diaconisa al Espíritu Santo, mientras que a los presbíteros [claramente desvalorizados en esta obra] los asimila a los apostoles, y a las viudas y huérfanos al altar... Evidentemente, no es éste el orden que acabó imponiéndose).

Por otra parte, el significado de la historia es muchas veces ambiguo, y por eso es frecuente que los historiadores difieran en la interpretación de un misno dato. Un proceder autoritario, por ejemplo, no revela ni significa lo mismo cuando se da en un mundo tremendamente jerarquizado que cuando se produce en un clima profundamente democrático. Y viceversa: una conducta de libertad no tiene la misma interpretación ni el mismo valor cuando se ejerce en una situación "piramidal" que cuando se ejerce en una situación de auténtica libertad. Pero de la historia conocemos y percibimos mucho más los datos aislados que los mundos o climas globales. Y tendemos a leer esos datos desde nuestros mundos respectivos. La mayoria de los datos que ahora aduciremos son, por eso mismo, ambiguos; pero ambiguos en ambos sentidos. Lo cual quiere decir que, si 
bien no constituyen pruebas decisivas para muchas aspiraciones modernas, tampoco lo son (y quizá menos) para algunas tesis antiguas.

Un ejemplo de cómo la historia es casi siempre manipulada por la inevilable parcialidad de nuestro acceso a ella, lo tenemos en este curioso detalle: el conocido Enchiridion de C. Kirch, que recoge las fuentes de historia de la Iglesia antigua y que ha sido libro de uso en tantos seminarios y facultades teológicas durante décadas, cuando llega a los Statuta Eclesiae Antiqua sólo recoge de allí un canon, referente a la celebración del matrimonio, en el cual se recomienda que los novios sean presentados por sus padrinos y se abstengan de tener relaciones sexuales la noche de la bendición nupcial. Sin menospreciar las buenas intenciones de este canon, quienquiera que haya leído esta breve obrita (en el ML 56, como apéndice a san León) habrá encontrado en ella otros cánones mucho más significativos, importantes e interpeladores para hoy (como el que prohibe a la Iglesia recibir dinero o donativo alguno de quienes oprimen a los pobres...). De cste tipo de ejemplos están llenos todos los manuales (comenzando por el mismísimo Denzinger). Y así, por los inevilables silencios y las necesarias preferencias, se configura una mentalidad que, aun creyendo ser "tradicional," quizá no es más que "expurgada."

Sé perfectamente que algo de esto mismo puede ocurrirle a la síntesis historica que aquí se presenta. Por eso, sus conclusiones son menos delinitivas de lo que algunos querrian. Pero pienso que quizá pone de relieve aspectos reales y, a la vez, olvidados.

Después de esta reflexiớn previa, volvamos a nuestro tema. Que la Iglesia se vaya estructurando cada vez más, conforme sale del Nuevo Testamento y entra en la historia, es esperable para una institución que crece entre persecuciones y que se va extendiendo a un ritmo llamativo por toda la oikoumenê. Lo sorprendente es que la estructuración va a ir adoptando la forma de una "clericalización." Este no es un proceso tardio, que sólo se haya iniciado a partir del segundo milenio, como a veces se da a entender, sino que tiene lugar ya en los seis primeros siglos de la Iglesia.

\section{Funciones en la "suerte" (kleros) del Señor}

El primer detalle que conviene poner de relieve es que en los dos primeros siglos de la Iglesia no hay "laicos," porque tampoco hay clero. La palabra "clero" conserva por entones su sentido etimológico (porción que corresponde en suerte), y designa así a toda la porción del Seflor, a toda la Iglesia. Equivale, sustancialmente, al pueblo de Dios. Mientras que la palabra "laico," como tal, no parece tener campo de aplicación en la Iglesia. Tan sólo aparece utilizada una vez (1Clem 40,5), pero en un texto que describe lo que ocurria en el Antiguo Testamento, cuyo modo de funcionamiento ha quedado superado por Cristo.

Esto no significa que Clemente no tenga una conciencia muy clara de la 
autoridad y del apostolado (y más aún, supuesta la necesidad de resolver la secesión producida en Corinto). Para vindicar esa necesidad de la autoridad, Clemente echa mano tanto de lo que ocurría en Israel como de lo que ocurre en la sociedad civil ( $c f .37,1-3)$. Pero no parece que esa conciencia haya de apoyarse en la distinción entre un clero que constiwye la porción propiamente eclesiástica y un laicado "profano" en eclesialidad. Y la razón de este hecho la formula así el mismo autor de quien hemos tomado el dato: para aquellas iglesias, la cenuralidad de Dios y de Cristo es tal que no admite la presencia de cualquier otro "centro" humano y, por tanto, impide que las lunciones comunitarias sean "propiedad de alguna institución humana que las centralice, para luego delegarlas."

De algunas de esas funciones se han conservado tesimonios, sobre lodo gracias a las defensas o descripciones de las primilivas eucaristías. ${ }^{44}$ En ellas se habla de "lectores," de un "presidente de los hermanos" (tô proestoti tôn adelphön) al que se presentan las ofrendas, quien recita la plegaria eucarística y reparte los alimentos y limosnas a los necesilados, y de unos "diáconos" que distribuyen el pan y el vino tras la oración del cilado presidente. A este último nunca se lo llama "sacerdote," "celebrante," "presbítero" ni "obispo," y es posible que este delalle lingüístico tenga algún significado teológico. Además, tampoco hay en estos textos indicio alguno de una presidencia eucarística establecida como función uniforme, cosa esla que tampoco se encuentra en Ireneo. ${ }^{65}$ Algo más en esta otra dirección podría apuntar 1Clemente 44,4 cuando dice que los presbíteros depuestos en Corinto "habian ofrecido dones piadosamente" (sobre todo, dada la concepción de esta carta de que, en todos los campos de la realidad, cada cosa tiene su función). Pero el único testimonio claro en este sentido to constituye, por lo que yo puedo saber, Ignacio de Antioquía, cuando escribe a los esmimiotas: "sólo se tenga por válida aquella eucaristía que se celebra bajo el obispo o aquel a quien él se lo encargue." Este texto merece un breve comentario, por dos razones:

Porque refleja la necesidad de la Iglesia de poder controlar la celebración eucarística. Una necesidad que se extiende hasta la validez misma de la eucaristia; y una necesidad comprensible, puesto que era una cuestión vital el poder asegurar que la Eucaristía se celebraba como eucaristia "de la Iglesia," reconocida por ésta como propia u "oficial." Ireneo ya da testimonio de algunas formas estrambóticas de celebración eucarística que montaban los gnósticos y que - por alusión a un problema semejante que tuvo la Iglesia con los evangelios - podriamos calificar de "apocrifas." $\mathrm{Y}$ las acusaciones paganas a que aludiamos en la nota 64 habían de obligar ambién a alguna forma de control. El mismo Ignacio dicta su norma tras aludir a algunos que "no confiesan que la Eucristfa es la carne del Salvador" (VIII,1).

Y porque, además, insinúa ya el enlace entre presidencia de la eucaristía y presidencia de la comunidad, puesto que, inmediatamente antes de la frase 
citada, acaba de decir lo siguiente: "que nadie, sin contar con el obispo, haga nada de cuanto atafle a la Iglesia." Esta fusión va a tener lugar de una manera clara en los siglos subsiguientes.

Pero, volviendo al hilo de nuestra reflexión, hemos de concluir que si bien Ignacio se ha planteado ya el problema del derecho a la presidencia eucarística, los otros tres testimonios (Justino, Ireneo y la Didache) sólo parecen testificar el hecho de dicha presidencia ${ }^{63}$ Su interés ha ido más bien por otros caminos; la estrutura de la celebración, las oraciones reciladas en ella, la presencia real y el hecho de que la eucaristía sustituye a todos los sacrificios antiguos, porque es celebrada por "la verdadera raza sacerdotal de Dios. ${ }^{n 69} \mathrm{Y}$ este detalle no deja de ser significativo.

Fuera de esto, apenas tenemos un par de testimonios más que nos digan algo acerca del lenguaje y la estructura del ministerio, y que vamos a evocar para cerrar este primer apartado.

Casi por casualidad, la Didaché nos testifica también la existencia de "apostoles y profetas" (XI,3-6); y lo hace para decir que no se les dé hospedaje más de un día o dos, y que al despedirlos se les dé pan, pero no dinero, porque, si lo piden, "son falsos profetas." Esta rápida pincelada es aún más sorprendente por el hecho de que la Didaché es un escrito preocupado por la hospitalidad cristiana ( $c f$. XII, 1ss). Con ello revela que ya hablan comenzado a aparecer los abusos entre los profetas: los antiguos carismáticos ambulantes se estaban convirtiendo ahora en vividores camuflados. Es la dura inercia de la historia...

También la Didaché encarga a las comunidades que se elijan inspectores y ayudantes (episkopous kai diakonous: XV,1-3). Y nos dice de ellos que "administran el ministerio de los profetas y maestros" (didáskalos, que equivale probablemente a los "apóstoles" de XI, 3). Son, pues, ministerios que difieren de los del párrafo anterior no por su campo de acción, sino por el caráler inmediato $o$ mediato de su trabajo. El autor recomienda a las comunidades que elijan a hombres "mansos, desinteresados y probados" (XV, 1). Es el primer testimonio de que tengo noticia acerca de la obligación de elegir a los ministros de las comunidades.

También Justino, en sus Apologlas, alude más de una vez a "doctores" que funcionan con una cierta autonomía Según Faivre, "las Apologfas de Justino revelan todavfa ese espiritu de libre iniciativa. Y, probablemente, solo a partir del momento en que los doctores cesaron de ser autónomos se les comenzó a llamar 'calequistas'."mo

No hay mucho más que decir. Pero esta siluación del siglo II merecía ser destacada, porque enseguida nos vamos a encontrar con que, a la entrada del siglo III, se va a producir un giro copernicano en dos de los puntos expuestos: en primer lugar, se va a operar una concentración en los ministros de la celebración 
eucarística (que ahora serán ya los "clásicos:" obispo, presbítero y diácono); y en segundo lugar, asistimos además a una aparición muy generalizada del término "laico" (en Clemente de Alejandría, en Tertuliano, en la Didascalía de Siria, o en carlas provenientes de Roma...) para designar a quienes no pertenecen a esa triada. Con lo cual estamos ya en una situación muy similar a la nuestra y que merece ser examinada un poco más detenidamente.

\section{Entre estructuración y libertad (siglo III)}

La gran ventaja, cuando se sale del siglo II, es que ahora se cuenta no sólo con muchos más testimonios, sino además con textos más cualificados. Pues no nos quedan tan sólo escritos "ajenos al tema" (v.g. apologélicos o narrativos...) y que aluden a él sólo de pasada, sino texlos de carácter más "canónico," que pretenden regular la praxis ministerial y normativizar la vida de la Iglesia; o texios que muestran el ejercicio de esa praxis, como son algunas cartas de san Cipriano.

Por lo que toca al primer tipo de textos, conviene reconocer que una ley no reproduce una vida ( $\mathrm{jmuchas}$ leyes se repilieron, precisamente porque no se cumplían!), pero al menos sí que refleja una mentalidad. Y esta mentalidad irá siendo cada vez más estructuradora y clericalizadora.

La abundancia de testimonios dificulta enomemente una exposición sintética, que no puede recorrerlos todos. Pero, al igual que ocurre con las carlas de Cipriano, tenemos un texto legal que constituye una fuente privilegiada. Me refiero a la Traditio Apostolica (T.A.) de Hipólito.

Los problemas que plantea este breve escrito no son pequeños. Pero parece que podemos afirmar su procedencia de la primera mitad del siglo III (Lal vez, hacia el affo 218), así como la existencia de una versión egipcia anterior a la versión latina que comentamos ${ }^{71}$ y la casi segura atribución de esta obra a Hipolito. De ella existen además otras versiones (copta, siria, árabe... y seguramente un original griego que se ha perdido), lo cual es indicio de su enorme difusión entre las iglesias del siglo III. Esto mismo testifican los muchos documentos derivados de ella (Constituciones Apostólicas, Eptiome, Canon de Hipólito... ).

Por otro lado, la atribución a Hipólito nos pone sobre aviso, ya a priori, acerca de la orientación del escrito. El autor es hombre conocido por su amor al "orden" y sus orientaciones severas. Llegó a ser el primer antipapa, por oponerse al papa Calixto en temas de suavidad disciplinar relacionados con la penitencia y el matrimonio. Parece ser que luego abdic6, pero quizá sólo el martirio lo libró de acabar siendo cismático. En el prólogo de la T.A. considera que ha llegado la hora de pasar "de la caridad... a la tradición." Y la obra consta de tres partes: una, sobre la elección y consagración de los obispos y sobre la eucaristia; otra, sobre los fieles y sobre el bautismo (esta 
composición ternática ya es de por sí significativa). La última parte trata de diversas costumbres cristianas.

Pues bien, de acuerdo con lo dicho, los datos que podemos espigar en la T.A. accrca de la forma del ministerio en el siglo III evidencian claramente un mayor afán estructurador y regulador. A pesar de todo, tanto en la misma T.A. como en otros datos que poseemos de la vida del siglo III aparecen huellas suficientes de que esa reciente estructuración coexiste todavía con amplios márgenes de libertad. Con ello tenemos enunciadas las dos partes de este apartado: control y libertad.

\subsection{Elementos de estructuración del ministerio}

Por extrafio que parezca, no consta en ninguna parte cuándo y cómo se desdobló el ministerio pastoral en "obispos" y "presbíteros," apartándose de lo que habla sido el léxico no diferenciado del Nuevo Testamento. Si en Ignacio de Antioquía encontrábamos ya esa distinción, aunque sólo como un testimonio suelso, ahora parece haberse convertido en un dato universal. El ministerio queda casi universalmente diferenciado y jerarquizado en obispos, presbíleros y diáconos. Y no sólo la T.A. da testimonio de ello.

Del mismo modo repentino, y no fácil de explicar, el siglo III testifica una concentración de esos ministerios en lo referente a la celebración eucarística (a la que ahora podemos llamar "culto" cristiano).

Esta doble concentración se refleja en dos puntos que conviene comentar.

En primer lugar, se refleja en un cambio de lenguaje sumamente importante: ahora son estos tres oficios los que reciben el nombre de kleros (la "porción del Sefior"), que probablemente es la palabra que Tertuliano traduce por ordo 12 y que da paso a nuestra actual expresión de "sacramento del Orden," cuyo significado resulta ya tan incomprensible para el cristiano medio.

El "retraso de la parusfa" parece haber tenido bastante que ver con este cambio. Con la no llegada del final de los tiempos, el mismo creyente tiene que volverse también a "lo temparal." Parece entonces que "porción del Seftor" sean sólo aquellos que se dedican expresamente a "las cosas del Sefior" y no a las suyas propias. Esta inferencia implkcita nos acerca mucho, una vez más, a la sibuación veterotestamentaria o "religiosa" general." Y la noción de "clero" (en su signifiado original) se va volviendo con ello más "verosímil" y más verificable que la de "pueblo de Dios."

En paralelismo con esto, asistimos también -como ya dijo- a una aparición súbita y muy extendida de la palabra laicos, para designar a aquellos que no pertenecen a esa triada de ministros. No obstante $(y$, al menos, segín la explicación de A. Faivre), el laicado del siglo III todavla no coincide con el del siglo XX: no tiene tanto significado de oposición al clero como de acercamiento 
a el. En realidad, la aparición del "clero" ha sido un mal, puesto que siguen siendo rodos los fieles los que deberian vivir como el clero, o "para el Seflor." Por eso hay algunos que tratarán al menos de acercarse a ese ideal imposible y de colaborar con él." "Laico" no es aqu, por tanto, el que no es "clero," en el sentido de que es profano, sino el que todavía quiere ser pueblo, y por eso se acerca a ser "porción del Seflor."

Además del cambio de lenguaje, otra expresión de esa concentración del ministerio la tenemos en lo que parece ocurrir con la imposición de manos, que ahora adquiere expresamente un doble significado jerarquizador que conviene ver más despacio.

Expliquemos antes que la concentración de funciones va a ir conduciendo a una de estas dos cosas: a que a veces queden "restos" de una función absorbida (v.g., el "doctor" es absorbido por el "presidente," pero queda un resto que pasa a convertirse en el "leclor;"76 y a crear a veces funciones auxiliares o ayudantes inferiores cuando una sola función no da abasto (así aparece, por ejemplo, el "subdiácono" y, probablemente, también el "ostiario," el acólito," etc.). En ambos casos tenemos lo que luego se llamarán "órdenes menores." Pero ahora la estructura es de delegación hacia abajo, más que de pluralidad de carismas unificados por el Espíritu, como formulábamos al hablar de Pablo.

Pues bien, en este estado de cosas se hace ya una clara distinción en el rito de la imposición de manos. La T.A. prescribe que no se impongan las manos si no es en relación con el ministerio eucarístico (por ejemplo, a las viudas). ${ }^{\pi}$ Frente a la "ordenación," aparece ahora la "instalación." Y lo de menos es si esa instalación se produce imponiendo las manos o no (como parece preferir Hipólito), pues incluso en el primer caso se tratará de una imposición de manos con significado distinto de la de los ministerios eucaristicos (to cual llevara a la distinción, incluso linguística, entre cheirotonia y cheirothesia, a la que ya aludimos).

Pero no es esto sólo lo más importante, sino que tanto Hipólito como Origenes, o la DidaskalLa, justificarán esa concentración y distinción... imediante el recurso a una ripologla veterotestamentaria!; presblteros y diáconos son asimilados a los "sacerdotes" y "levitas" del Antiguo Testamento. Origenes, más amante de la alegoria, recurrirá a la imagen del Sumo Sacerdote que penetraba solo en el Santo de los Santos. ${ }^{76}$ Hemos de añadir, no obstante, que el recurso a la nomenclaura veterotestamentaria es, al menos en los comienzos, bastante elástico e impreciso. Asf, por ejemplo, la Didaskalla (II, 26, 2 y 3), a la vez que reconoce que "sólo ofrecen los obispos," añade a continuación que "vuestros sacerdotes son los diáconos, los presbiteros, las viudas y los huerfanos." Es de lamentar que esa sacerdotalización de los pobres ("viudas y huérfanos"), que habría compensado la trayectoria clerical, no se haya impuesto en la historia de la Iglesia posterior. 
composición temática ya es de por sí significativa). La úlima parte trata de diversas costumbres cristianas.

Pues bien, de acuerdo con lo dicho, los datos que podemos espigar en la T.A. acerca de la forma del ministerio en el siglo III evidencian claramente un mayor afán estructurador y regulador. A pesar de todo, tanto en la misma T.A. como en otros datos que poseemos de la vida del siglo III aparecen huellas suficientes de que esa reciente estructuración coexiste todavía con amplios márgenes de libertad. Con ello tenemos enunciadas las dos partes de este apartado: control y libertad.

\subsection{Elementos de estructuración del ministerio}

Por extrafio que parezca, no consta en ninguna parte cuándo y cómo se desdobló el ministerio pastoral en "obispos" y "presbíleros," apartándose de lo que había sido el léxico no diferenciado del Nuevo Testamento. Si en Ignacio de Antioquía encontrábamos ya esa distinción, aunque sólo como un testimonio suelto, ahora parece haberse convertido en un dato universal. El ministerio queda casi universalmente diferenciado y jerarquizado en obispos, presbíteros y diáconos. Y no sólo la T.A. da lestimonio de ello.

Del mismo modo repentino, y no lácil de explicar, el siglo III testifica una concentración de esos ministerios en lo referente a la celebración eucarística (a la que ahora podemos llamar "culto" cristiano).

Esta doble concentración se refleja en dos puntos que conviene comentar.

En primer lugar, se refleja en un cambio de lenguaje sumamente importante: ahora son estos tres oficios los que reciben el nombre de kleros (la "porción del Sefior"), que probablemente es la palabra que Tertuliano traduce por ordo 12 y que da paso a nuestra actual expresión de "sacramento del Orden," cuyo significado resulta ya tan incomprensible para el cristiano medio.

El "retraso de la parusía" parece haber tenido bastante que ver con este cambio. Con la no llegada del final de los tiempos, el mismo creyente tiene que volverse también a "lo temparal." Parece entonces que "porción del Sefhor" sean sólo aquellos que se dedican expresamente a "las cosas del Sehor" y no a las suyas propias. Esła inferencia implicila nos acerca mucho, una vez más, a la situación veterotestamentaria o "religiosa" general." Y Y la noción de "clero" (en su signifiado original) se va volviendo con ello más "verosímil" y más verificable que la de "pueblo de Dios."

En paralelismo con esto, asistimos también -como ya dije- a una aparición súbita y muy extendida de la palabra laicos, para designar a aquellos que no pertenecen a esa trada de ministros. No obstante $(y$, al menos, según la explicación de A. Faivre), el laicado del siglo III todavia no coincide con el del siglo XX: no tiene tanto significado de oposición al clero como de acercamiento 
a él. En realidad, la aparición del "clero" ha sido un mal, puesto que siguen siendo todos los fieles los que deberían vivir como el clero, o "para el Señor." Por eso hay algunos que tratarán al menos de acercarse a ese ideal imposible y de colaborar con el." "Laico" no es aquí, por tanto, el que no es "clero," en el sentido de que es profano, sino el que todavía quiere ser pueblo, y por eso se acerca a ser "porción del Señor."

Además del cambio de lenguaje, otra expresión de esa concentración del ministerio la tenemos en lo que parece ocurrir con la imposición de manos, que ahora adquiere expresamente un doble significado jerarquizador que conviene ver más despacio.

Expliquemos antes que la concentración de funciones va a ir conduciendo a una de estas dos cosas: a que a veces queden "resios" de una función absorbida (v.g., el "doctor" es absorbido por el "presidente," pero queda un resto que pasa a convertirse en el "lector," inferiores cuando una sola función no da abasto (así aparece, por ejemplo, el "subdiácono" y, probablemente, lambién el "ostiario," el acólito," elc.). En ambos casos tenemos lo que luego se llamarán "ordenes menores." Pero ahora la estructura es de delegación hacia abajo, más que de pluralidad de carismas unificados por el Espíritu, como formulábamos al hablar de Pablo.

Pues bien, en este estado de cosas se hace ya una clara distinción en el rito de la imposición de manos. La T.A. prescribe que no se impongan las manos si no es en relación con el ministerio eucarístico (por ejemplo, a las viudas). ${ }^{n}$ Frente a la "ordenación," aparece ahora la "instalación." Y lo de menos es si esa instalación se produce imponiendo las manos o no (como parece preferir Hip6lito), pues incluso en el primer caso se tratará de una imposición de manos con significado distinto de la de los ministerios eucaristicos (lo cual llevará a la distinción, incluso lingüística, entre cheirotonia y cheirothesia, a la que ya aludimos).

Pero no es esto sólo lo más importante, sino que tanto Hipólito como Orígenes, o la Didaskalla, justificarán esa concentración y distinción... imediante el recurso a una tipología veterotestamentaria!; presbíteros y diáconos son asimilados a los "sacerdotes" y "levitas" del Antiguo Testamento. Orígenes, más amante de la alegoría, recurríra a la imagen del Sumo Sacerdote que penetraba solo en el Santo de los Santos. ${ }^{\text {"t }}$ Hemos de añadir, no obstante, que el recurso a la nomenclatura veterotestamentaria es, al menos en los comienzos, bastante elástico e impreciso. Asf, por ejemplo, la Didaskalla (II, 26, 2 y 3), a la vez que reconoce que "sólo ofrecen los obispos," añade a continuación que "vuestros sacerdotes son los diáconos, los presbíleros, las viudas y los huérfanos." Es de lamentar que esa sacerdotalización de los pobres ("viudas y huérfanos"), que habría compensado la trayectoria clerical, no se haya impuesto en la historia de la Iglesia posterior. 
Estructuración, clericalización y léxico sacerdotal han nacido juntos. El tiempo habra de decidir qué hay aqui de recuperación legitima del Antiguo Testamento y qué hay de recalda en el mismo (como formulábamos en nuestra primera parte). De momento nos basta con el dato escueto. Ahora hemos de ver la segunda de las partes anunciadas.

\subsection{Márgenes de libertad}

Si en los puntos arriba descritos, la situación del siglo II anticipa ya nuestra situación actual, hay que añadir que los datos que tenemos de este siglo difieren también de esa nuestra situación actual por la fexibilidad y la cantidad de espacios libres que aún conserva aquella situación ya más estructurada. Y conviene enumerar algunos de dichos espacios, porque pueden tener una importante signficación teológica.

Para comenzar por lo más simple, cuando Hipólito propone su famosa plegaria eucarística, que coincide sustancialmente con el canon segundo de nuestras misas, advierte expresamente que "no es en absoluto necesario que (el obispo) diga las mismas palabras que hemos propuesto, como si se tratara de hablar de memoria al dar gracias (eucharistein) a Dios. Que cada cual rece según sus capacidades... (más prolongada o más brevemente), con tal de que su plegaria sea sana en ortodoxia" (T.A. 9).

Las versiones árabe y egipcia han suprimido este texto, o bien la partícula no, de modo que convierten en "absolulamente necesario el repetir las mismas palabras." Ello da testimonio de una situación varios siglos más tardía y que se acerca más a nuestra rigidez actual. En cambio, a Hipólito le interesa más la oración que la formula, con tal de que se eviten fórmulas de inspiración monarquista o modalista (a eso parece aludir la referencia a la "sana ortodoxia").

Más importante aún, Hipólito reconoce probablemente la posibilidad de que presidan la eucaristra hombres sin ordenación, como son los "confesores" (o mártires que hablan salido con vida de la tortura): al confesor "no se le han de imponer las manos para el diaconado ni para el presbiterado, pues por su martirio ya posee el honor del presbiterado" (T.A. 9). Tal vez sigue latiendo aqui una concepción (hoy perdida) seguin la cual la ordenación no es tan solo colación de un poder, sino que puede ser también reconocimiento de un don: hay un grado de apostolicidad "material" o de identificación con Jesús que puede suplir incluso la falta de plena apostolicidad formal. ${ }^{79}$ Pero también es probable que el texto de la T.A. no tenga la fuerza que le atribuimos hoy identificando "presbitero" y "presidente" de la Eucaristí. ¿Supone Hipolito esa identificación? ¿O piensa que sólo el obispo es ministro de la Eucarisúa? Y en la segunda hipótesis, ¿lo concibe como único ministro posible o sólo como presidente habitual (lo cual no excluirla otros presidentes "extraordinarios")? Nuestro texto no bo deja claro. Pero sí conviene notar que la T.A. afade expresamente que, "en cambio, si se lo 
nombra obispo (al confesor), que se le impongan las manos" (T.A. 9). Esta diferencia tiene pleno sentido, incluso al margen de las preguntas anteriores, y no sólo porque el número de obispos es mucho más reducido y debe ser, por ello, más controlado, sino para permilir la participación del pueblo en la elección del responsable último de cada Iglesia, de lo cual luego hablaremos.

Y esta posible y sorprendente excepción de la T.A. no es única. En otro texto famoso. Tertuliano sostiene que la necesidad de la ordenacción es sólo de carácter disciplinar, pero que por sí mismos ( $y$ alli donde otra cosa no sea posible) el clérigo y el laico siguen siendo iguales a la hora de la Eucaristra.

¿Acaso los laicos no somos sacerdotes? Está escrito que 'hizo de nosotros un reino de sacerdotes para su Dios y Padre' (Apoc 1,6). La diferencia entre el orden y el pueblo la constituyó la autoridad de la Iglesia, y el poder ha sido santificado por la asamblea del orden sacerdotal. Hasta el punto de que, cuando falta esa asamblea del orden eclesiástico, tí puedes ofrecer y bautizar, y eres sacerdote tú solo para ti. Pero donde hay tres, allí está la Iglesia, aunque sean laicos. ${ }^{80}$

La fuerza de este texto radica en que su testimonio no es intencionado, sino indirecto. Tertuliano no está disculiendo de clérigos y laicos, sino de las segundas nupcias. Y quiere probar que la prohibición de éstas afecta también a los laicos (cosa que no se aceptaba en la Iglesia de su tiempo). Por eso busca argumentar a partir de datos aceptados por todos. $Y$ arguye, igual que a la hora de la Euaristla tienes (de iure, al menos) los mismos poderes que el clérigo, asi también a la hora de la monogamia tienes sus mismas obligaciones.

Podrá objetarse que quizá se trata de un texto del Tertuliano montanista y no católico. El De exhortatione castitotis está fechado entre los affos 204 y 212, y Tertuliano se hizo montanista entre el 207 y el 208. Es posible, pues, que la obra sea montanista. Pero lampoco está claro si ya a priori puede decirse que el contenido del texto es montanista, independientemente de cuál sea su fecha Pues el montanismo parece ser una mezcla de rigorismo, anarquismo y elitismo carismático, no fácil de reconstruir por pura deducción. La fuerza del texto de Tertuliano puede residir en el hecho de que se dirige a todos (no sólo a los santos y carismáticos) y argumenta como citando un dato conocido y aceptado por sus rivales.

Más aún, para acabar de complicar las cosas, Firmiliano, obispo de Cesarea de Capadocia, en una carta a san Cipriano nos da un testimonio parecido, pero esta vez referido a una mujer. Se trata de una sefiora que "se presentaba como profetisa y se comportaba como invadida por el Espritu Santo, aunque luego se descubrió que era una impostora de vida disoluta (que, por ejemplo, "enganó a un presbftero rural y a un diácono para que tuvieran relaciones con ella"). Pues bien, de esta mujer nos dice Firmiliano que se "atrevió repetidas veces a fingir 
que con su invocación eficaz consagraba el pan y realizaba la eucaristla y ofrecia al Señor el sacrificio con el rito de las palabras acosumbradas, y bautizaba a muchos con la fórmula usual."

La fuerza - y la insuficiencia- de este texio parece estar en que su autor no cuestiona para nada lo referente a la Eucaristfa. A Fimiliano le interesa el tema del bautismo, que era el que enfrentaba entonces a Cipriano con el obispo de Roma, Esteban. La carta es una durisima diatriba contra este último y contra su rigor y severidad para con Cipriano en este punto. Por eso Firmiliano prescinde de la Eucaristía y lanza enseguida la pregunta: lacaso podemos crcer que el demonio bautizaba por medio de esta mujer, y que a ese bautismo seguran el perdón de los pecados y la gracia de la Trinidad, dado que su fórmula era la correcta? ¿Aceptaría el papa Esteban la validez de ese bautismo? ${ }^{22}$

En mi opinión, el argumento no es válido. Téblogos posteriores quizás habrian dicho que faltaba en aquella mujer aprovechada la "intención de hacer lo que hace la Iglesia" (y por eso podía el papa haber rechazado los bautismos de tal mujer y reconocer los de los herejes, en los que él sI vela presente dicha intención). ${ }^{\text {e3 }}$ Pero lo importante para nuestro tema no es eso, sino esta otra cuestión: ¿podría Firmiliano presentar ese testimonio si la mera idea de una mujer presidiendo la Eucaristía hubiera sido totalmente impensable - por estrambótica - en la Iglesia de aquel tiempo? De darse esta total improbabilidad, la anécdota que aduce Firmiliano pasarfa, con toda razón, por no histórica, ${ }^{\text {et }}$ con lo que se habra quedado sin premisa para su argumento.

Hemos recogido en esie apartado los textos que más dificultad pueden ocasionar a la siluación actual. $Y$ aunque son demasiado pocos para imponer una conclusión como necesaria, bal vez sean suficientes como para merecer atención y estudio, por si abren algún carnino como posible. De momento -y dejando todo por resolver, porque los dalos no dan más de si-, hemos de pasar a un tercer apartado, mucho más claro e interpelante.

Este tercer punto a examinar es el que se refiere a la elección de los ministros. También aqu se introduce un espacio de equilibrio en la estructuración que hemos presentado. La intervención del pueblo en la elección del obispo es, para san Cipriano, "tradición divina" y "práctica apostólica." la razón por la que la T.A. decide que el confesor, por meritorio que fuera su martirio, y aunque no requiera la ordenación para ser presbítero, si la requiere, en cambio, para ser obispo.

Se trata aqui de un principio fundamental para la Iglesia primitiva, y en realidad proviene de una ordenación más amplia, que no afecta sólo a la elección de los obispos, sino a la participación del pueblo y a la consula de éste en las 
decisiones de la Iglesia ${ }^{86}$ Esta práclica -en la que también san Cipriano fue modelo y ejemplo, y que empalma con el modo de proceder de los apostoles que veíanos en los Hechos - se irá haciendo cada vez más difícl. Y ello no sólo por el detalle (accidental) de que algunos "confesores" se aprovecharan de ella y del respeto que les tenía la comunidad para hacerle casi imposible a Cipriano el gobiemo de su iglesia," sino (más estructuralmente) porque, en la medida en que la Iglesia va cobrando conciencia de su universalidad ("catolicidad"), muchas decisiones que afectan a una iglesia se van tomando fuera de cada comunidad local (en sínodos interdiocesanos, etc.), con lo que éstas no pueden ser fácilmente consultadas. Pero el principio subsiste, y Cipriano trala al menos de superar esas dificultades dando una información cumplida y detallada a su pueblo. ${ }^{\text {s }}$

Y este principio más amplio de la participación del pueblo es correlativo de otro que también tiene raíces neotestamentarias, como es la autonomía de las diversas iglesias locales en su configuración. Según la teología subyacente a ese principio, cada Iglesia local es, de algún modo, toda la eckklesía, excepto en lo que respecta al obispo, el cual tiene una responsabilidad más amplia y, por ello, puede ser lazo de unión (no sólo de su comunidad, sino) entre las diversas iglesias locales. El obispo no es sólo para la Iglesia local ni sólo de la Iglesia local. Aquí se insinúa una colegialidad germinal, que se manifiesta en la ceremonia de consagración del obispo: aunque la comunidad participa en su elección, sin embargo, la ordenación no corre a cargo de la comunidad, sino de los obispos de las iglesias vecinas. En este punto, Cipriano y la T.A. coinciden con la Iglesia de Roma.

Donde hay más autonomía suele haber mayor creatividad, y ésle es el último punto que nos queda por ejemplificar.

El afán de estructuración y de control durante este siglo no llegó al extremo de ahogar totalmente el daw -que ya hemos encontrado en el Nuevo Testamento- de que los ministerios nacen muchas veces vinculados a necesidades históricas concretas. Según la Didaskalía de Siria, la existencia de las diaconisas parece haber tenido que ver con exigencias bien prácticas, como era la conveniencia de evitar escándalos a paganos (en las visitas a mujeres) o de evitar atentados al pudor en los bautismos por inmersión:

Búscate, oh obispo, trabajadores de justicia como auxiliares que puedan ayudar a la salvación de tu pueblo. A quienes te agraden de entre todo el pueblo, los escogerás y los establecerás como diáconos: un varón para la ejecución de las muchas cosas que son necesarias, y una mujer para el servicio de las mujeres. Porque hay cosas a las que no puedes enviar a un diácono entre las mujeres, por causa de los paganos, pero puedes enviar una diaconisa Y también porque en otras muchas cosas es necesario el oficio de una mujer-diácono. En primer lugar, cuando las mujeres bajan al agua tienen 
que ser ungidas con el bleo de la unción por una diaconisa. Si no encuentras a ninguna mujer, sobre lodo diaconisa, que le de la unción el que la bautiza; pero, si hay alguna mujer, sobre todo diaconisa, no esta bien que los varones vean a las mujeres... Y cuando la bautizada salga del agua, que la acoja la diaconisa y que ella le ensefte cómo tiene que ser conservado el sello del bautismo totalmente intacto, en la pureza de la santidad."

\subsection{Lecciones de la historia}

Toda esta acumulación un tanto informe de datos sugiere algmos importantes puntos de reflexión teológica que vamos a reducir a tres grandes caploulos.

Estructuración necesaria. Veremos más adelante cómo todo este proceso de estructuración comporta sus peligros, y muy serios. Lo cual no quiere decir, en modo alguno, que no sea necesario y que no venga en buena parte impuesto por la nauraleza misma de las cosas. La historia humana es asl y hay en ella poces cosas necesarias que no sean a la vez peligrosas (sobo el talento infecundo y enterrado carece de riegos). Ello do lugar en la historia, unas veces, a pasos alocados, que avanzan sin medir los riesgos (hasta que terminan pagando factura, en lugar de llegar a la meta); y otras veces, a conservadurismos increyentes, que se paralizan por no correr riesgos (hasta que acaban conservando fósiles y perdiendo la vida que pretendian conservar). Y esta consideración, que es bien obvia, tiene que ver, sin embargo, con nuestro tema. Sería ingenuo pensar que una Iglesia que vive amenazada por las persecuciones y las herejias (que en estos primeros siglos son mucho más que discusiones tectricas, y amenazan con desintegrar la comunidad) no sienta la necesidad de apiflarse y de tener un eje en torno al cual hacerlo..$^{\circ}$ Esto es lo que fueron siendo cada vez mís los obispos, to cual puede explicar teológicamente la aparición del episcopado monárquico, prescindiendo de cómo se explique históricamente. Y a ello se aradía, ademís, otra serie de demandas practicas. Por ejemplo: las iglesias iban creciendo en número y en bienes, y el obispo fue convirtiéndose en un administrador fiable de la comunidad cristiana. Toda la evolución que aqui se inicia podrá, en otra época, presentar sus contraindicaciones, que convendrá corregir entonces. Pero no se puede presentar toda la progresiva institucionalización del ministerio eclesial como una simple apostasia respecto de un pretentido "espontaneismo evangélico" de los orfgenes, porque ello equivaldría a confundir a la Iglesia con aquel nitho de El tambor de hojalata, de Günter Grass, que se negaba a crecer porque no quería pagar el precio del crecimiento. Lo cual -repito- en modo alguno significa que el crecer no tenga sus riesgos que hay que procurar evitar y corregir.

Historicamente hablando, me parece exacto el siguiente balance de J. Rius:

Entre los documentos más arcaicos y primitivos y los más tardíos, se observa una notable evolución en lo que concieme a la proliferación, estratificación y 
especialización de los diversos ministerios tanto masculinos como femeninos. Pero, a la par que se da esta evolución, se observa otra no menos interesante: se da un proceso de progresiva imitación, primero de las comunidades judias, en lo que concieme a la organización de la comunidad en sus variadas funciones y celebraciones, para terminar después en una férrea organización a base de estereotipos en los que la función ha dado paso ya a la titularidad, y la celebración al ritualismo cultual. Este fenómeno observado en la presente muestra de escritos, pertenecientes de alguna manera al área siro-helenista, debería estudiarse detenidamente y a gran escala, ampliándolo a otros escritos de corte análogo a los aquí estudiados."1

Pero, a la vez, es un balance teologicamente esperable. Y, sin hacer esa minuciosa ampliación del estudio que programa el autor, se puede esperar que los resultados se acercarán bastante a lo que él encuentra en el área sirohelenista, en sus aciertos y en sus riesgos. Sólo que esto de ninguna manera signilica que tal evolución deba ser canonizada por nosotros como normaliva para hoy en todos sus aspectos. Significa tan sólo que la misión del téblogo, cuando dialoga con la historia, no es condenar ni canonizar la historia, sino aprender de ella para arreglar el presente.

Por eso, una vez establecida la necesidad de esta evolución, vamos a intentar aprender de sus aciertos y de sus contraindicaciones.

Colegialidad no perdida. El rasgo más significativo de la estructuración del ministerio en obispos-presbíteros-dí́conos quizá sea el carâcter colegial del presbiterado (el cual, a su vez, es un reflejo del carácter colegial del episcopado). Este dato permanece inalterado desde la primitiva comunidad de Jesusalén y nos permite establecer un principio teológico importante: la Iglesia es colegial y, mirada ad intra, la estructura del ministerio es también colegiada. Como escribe Karl Rahner.

De hecho, ya el NT y la Iglesia más antigua no conocen sacerdotes parliculares, sino presbiterio. (...) Si este segundo grado de ministerio sacerdotal es realmente iuris divini, no podrá ser concebido sino como colegio para el obispo. Los sacerdotes, por tanto, no sustituyen en primera línea al obispo donde éste no está, sino que, en cuanto presbiterio, le apoyan allí donde estr.92

Este dato habrá de coexistir con otros, pero no puede ser borrado por ellos. $Y$ ni la necesaria cabeza de todo colegio ni la enorme dificultad de una realización práctica de lo colegial en colegios muy numerosos pueden hacerlo desaparecer, porque lo que la Iglesia recibió de Jesús fue precisamente, y tan sólo, un ministerio colegiado: el colegio apostólico. El papa y el obispo son, por supuesto, cabeza de sus respectivos colegios, pero ni uno ni otro pueden ejercer su capitalidad reduciendo el colegio a una especie de "ordenes menores," porque 
entonces ya no serian cabeza, sino rodo el organismo. Cosa que hoy parece ocurrir con más frecuencia de lo conveniente.

Y, curiosamente, un factor que parece haber influido en este negativo estado de cosas será la posterior "sacerdolización" ontológica del ministerio que denunciábamos en la primera parte de este escrito. Pues, al producirse ésta, el ministro lue siendo considerado cada vez más en sí mismo y por si mismo, al margen de su integración colegial, que es constitutiva de su ministerio (precisamente en cuanlo "hombre de la comunidad," la cual se estructura como "comunidad de comunidades").

Y esta última observación es la que nos lleva ahora a reflexionar sobre otro de los datos que se destacan en este siglo III: la casi wal concentración de los ministerios en la celebración eucarística.

Eucaristía y autoridad. Decíamos al comienzo del apartado 2.1. que no es fácil explicar cómo se produce esa concentración de los ministerios en tomo a la eucaristia. El argumento de que en la última cena sólo estaban presentes los apóstoles, y que, por lo tant, sólo a ellos se encomienda el encargo del Sefior, es exegéticamente muy forzado. Pero ahora quisiéramos mostrar que, aunque difícil de explicar para el historiador, este fenómeno tiene sus posibilidades de comprensión para el teólogo. La Iglesia percibió con agudeza que debe darse una necesaria consonancia entre "presidir la eucaristía" y "presidir la comunidad" (y quizá mayor aún en los momentos de persecución o de dificultad). Porque la autoridad en la Iglesia debería ser siempre como la presidencia en la eucaristia: una manera de hacer presente y vivo el recuerdo de la vida entregada de Jesús, para que ese recuerdo cree comunión; una presidencia que no es "propiedad privada," de modo que el presidente pueda "negar la comunión" a quienes "no son de su línea" o no comulgan con él (como si el comulgar con él equivaliera sin más a comulgar con Crisio). La eucaristua anticipa así simbólicamente la conversión de la autoridad mundana en autoridad evangélica. $Y$ por eso resulta coherente y expresiva la aproximación o identificación entre presidente de la comunidad y presidente de la eucaristia: porque "la eucaristía hace a la Iglesia, y la Iglesia hace a la eucarisúa" (De Lubac).

Pero todo esto, que parece innegable, no dejará de tener sus peligros. Y estos peligros comenzarán a actuar conforme la eucaristía vaya siendo concebida no ya desde el ephapax de Jesús (Heb 9, 12), que lleva necesariamente a la misión y hace misionera a la Iglesia, sino en perfecta univocidad con la categoria religiosa de "culı," la cual puede prescindir totalmente de la misión. Entonces la presidencia de la eucaristía no servira ya para corregir evangélicamente la presidencia de la comunidad, sino para divinizar arbitrariamente la autoridad desde la noción religiosa de lo "sacerdotal." Entonces, como escribe acertadamente A. Faivre, el fiel irá pasando, "de pertenecer al pueblo de sacerdotes, a ser pueblo de 
los sacerdotes. ${ }^{.93}$

Que hoy estamos más o menos en esta otra situación, me parece cierto. Aquí se manifiestan lo que antes denominábamos "contraindicaciones" de loda evolución histórica, que deben ser corregidas con el tiempo. Pero esta observación nos saca ya del siglo III. Queda por expresar la sospecha de si con esto no se produce también una desfiguración progresiva de la "ordenación." Parece que, en los comienzos, la imposición de manos fue necesaria para confiar la misión de aglutinador de una comunidad que, a su vez, era ella misma misionera (así lo veíamos en nuestro balance del Nuevo Testamento). Con el acercamiento entre esa tarea y la presidenia eucarística (más la necesidad de controlar la eucaristia, que veíamos a propósito de Ignacio de Antioquía), parece que se produce un desplazamiento casi total de la ordenación, desde el apostolado, hacia la eucaristía, dando lugar a la idea de transmisión de un "poder cúltico o sagrado." Y entonces ese poder sagrado se irá convirtiendo en fundamento único de la autoridad, la cual, anteriormente, tenía parte de su fundamentación en la aceptación por parte del pueblo, que era condición necesaria para la ordenación. Este hipotético cambio de significado de la ordenación es otra de esas cuestiones que deberían ser estudiadas más delenidamente. Lo cual implicará una recuperación del aspecto misionero de la eucaristía ("anunciamos"... "proclamamos"...). Pues, si la eucaristia no fuese misionera, no podría ni constituir a la Iglesia ni ser constituida por ella.

Nos hemos detenido ampliamente en este siglo porque probablemente es el más importante en toda la evolución del ministerio. Los siglos siguientes sólo van a umer consolidaciones y detalles ulteriores de este movimiento fundamental.

\section{Jugtificación y sistematización en el siglo IV}

El siglo IV no aporta datos que sean de gran interés, pues tiene cierto carácter de continuidad, aunque también de novedad, con respecto al siglo III. La continuidad viene dada por la dinámica misma de la evolución iniciada en el siglo anterior. La novedad deriva de la nueva y pacífica relación de la Iglesia con el imperio, relación alumbrada por Constantino y que ha creado una situación de:

-libertad, tan inaudita, tan anhelada y tan recién estrenada que es idealizada como si significara la llegada del reino;

$\rightarrow$ masificación, derivada del incremento casi obligado de conversiones, pero con la consecuencia de una progresiva degradación en los niveles de sequela lesu de la Iglesia;

-nuevo ripo de conflictos con las autoridades, y en concreto con los emperadores. Ahora, las autoridades no son perseguidores exteriores, sino simpatizantes, protectores y hasta miembros de la propia Iglesia. Pero ello 
Lampoco ahorrará las tensiones.

Estos nuevos factores no sólo crean problemas nuevos, sino que además condicionan la evolución de los antiguos. Con todo, podemos afirmar que, por lo que toca a nuestro tema del ministerio eclesial, esta evolución apunta netamente a una doble meta: estructurar, por un lado, y justificar teológicamente, por otro, la nueva siluación que ha ido apareciendo.

Veremos primero estos dos aspectos de la línea continuadora, para abordar luego, muy brevemente, algunos de los nuevos problemas de la relación con el imperio en lo que atane a la figura del ministerio eclesial.

\subsection{Sistematización de la situación anterior}

Lo que más quisiera subrayar de esta sistematización —para empalmar con algo ya comentado - no es tanto su contenido, sino cómo puede acabar teniendo, a la larga, consecuencias muy discutibles, aunque sea en si misma perfectamente comprensible y hasta loable. Por eso formulare diciendo que un lógico afán de santidad, de experiencia y de evitar abusos va a ir poniendo las bases para uno estructuración del ministerio como "separación" como "carrera" y como "control." Veamos estos tres puntos.

\section{Afán de santidad}

Una vez localizado el ministerio en aquella triada concentrada en tomo al altar, es lógico pensar que la Iglesia se preocupe por la santidad de vida de quienes están en "el santo de los santos." Pues, a pesar de que b eucaristía se vaya cultualizando, la Iglesia conserva cierta conciencia de que la santidad de Dios no está en el rito, sino en la vida.

Y a esto hay que anadir un par de factores que tal vez influyeran aún más en este afán de santidad. El primero es la práclica del perdón. Se piensa (desde el impacto de los mártires) que es por los santos por quienes Dios nos perdona a todos los demás. Y el perdón lo otorgan los ministros del altar, porque la reconciliación con la comunidad se expresa y realiza mediante la comunión eucaristica ¿No reclama esto la santidad de quienes otorgan ese perdón?

El segundo factor es, otra vez, el problema de los confesores, cuya santidad (derivada de su testimonio) les daba ante la gente una gran autoridad interior. Ya hicimos notar cómo algunos abusaron de esta auloridad en la cuestión de los lapsi . Ahora que ya no hay persecuciones, los que quedan tienden a abusar mucho más. Asl, se permiten a veces recomendar o incluso reconciliar por su cuenta, etc. También hernos visto que esto supuso problemas para los dirigentes de las comunidades. Afladamos ahora que también los obligó, a la vez, a "no ser menos santos."

Digamos a úfulo de ejemplo que, como consecuencia de este afán, se irá 
produciendo un progresivo acercamiento de los ministros a los monjes (que nacen ahora como protesta contra la mundanización de la Iglesia y como búsqueda de un sustitutivo del maririo). ¿Quién puede dedicarse a la Iglesia y ser el hombre de la comunidad mejor que quien ha decidido consagrarse a una vida radicalmente evangélica? ¿No está toda la razón de ser de la Iglesia en el evangelio?

Y este acercamiento es el que irá llevando a imponer la continencia, dado que los hombres de la comunidad no pueden retirarse al desierto. Una imposición que es más suave en oriente y más firme en occidente (si bien en occidente se da por supuesla la laicización o "secularización" para aquel que no cumpla), pero que se apoya en el mismo principio de acercamiento a los monjes y, a través de ellos, a los mártires o confesores.

Sólo que esta continencia, a la larga, va a ir marcando una barrera de separación entre ministerio eclesial y pueblo (dato a retener para más adelante). Una barrera que no deriva tanto de lo que el celibato pueda "marcar" la psicología de la persona, cuanto del hecho innegable de que crea estados de cosas tales que no resulta fácil pasar del uno al otro (v.g., por responsabilidades familiares, y porque quizá pueda imponerse el celibato a un ministro escogido, pero ya no se le puede imponer a su mujer, si es que está casado).95

Aś́ tenemos que el comprensible afán de santidad va a ir contribuyendo, a la larga e inesperadamente, a una configuración del ministerio como grupo separado del pueblo. Sin quererlo, la castidad lleva a la casta, a menos que esta sibuación se compense por otro lado.

\section{Afán de experiencia}

Se intenta lambién que, para llegar a formar parte del clero, se pase previamente por todas las tareas de la comunidad. Afán comprensible no sólo por razones de ejemplaridad, sino también de experimentación. Así, por ejemplo, Nicea legislará que no se ordene obispo a un neófilo, reafirmando con ello una línea que ya encontrábamos en las cartas pastorales.

Pero a la larga -y contra pronóstico- esto irá conduciendo a una devaluación de esas tareas en sí mismas, al mirarlas sólo como situaciones interinas o de paso. Se inicia así una evolución que irá convirtiéndolas en peldaños de un escalafón o de una carrera: de ser servicios, irán pasando a ser elapas. Y ello irá dando lugar, a su vez, a sensibilidades de protocolo, de las cuales es buen testimonio lo que regula el canon 18 de Nicea: que el diácono no dé la comunión al presbítero, ni tome asiento más cerca que éste del obispo, ni toque las especies delante de este último. Por debajo de esta reglamentación es fácil adivinar rencillas latentes de dignidad. Y la razón que se da para ello expresa ahora muy claramente que el diácono "no tiene polestad de ofrecer," y que es "inferior" al 
presbittero, a pesar de su estrecha vinculación al obispo: scientes quod episcoporwm ministri sunt, presbyteris autem inferiores probentur. ${ }^{96}$

\section{Necesidad de mayor control}

Hablo de "necesidad," porque precisamente la nueva situación de la Iglesia iba haciendo brotar ciertos privilegios civiles para las funciones eclesiásticas (v.g., en materia de impuestos, etc.). Ello no tardaría en provocar una inflación de estas funciones ( $y$, en concreto, de las llamadas "menores:" lector, etc.), con la consiguiente necesidad de controlarlas más para evitar "aprovechados."

Con ello irá apareciendo:

-una estructura más rigida y fija, que impide la creación libre de funciones según necesidades; y no sólo la "creación," sino también el trasvase de funciones de un lugar a otro." Este principio -aplicable a cualquiera de las tres funciones - llegó a ser tan serio que, luego de Nicea, Gregorio Nazianceno fue obligado a dejar la sede de Constantinopla por haber sido antes obispo de otra ciudad. A la larga (como cabía esperar) quedó sin cumplirse;

-una ceremonia de "instalación" mucho más controlada, ritualizada y obligatoria (ahora incluso con imposición de manos - no "ordenaloria" - hasta para las funciones "menores," lo cual irá justificando el que también se las llame "órdenes");

- y, con lógica bien comprensible, una extensión de la palabra "clero" a estas funciones u "órdenes" menores. Esto se refleja en el canon 109 de Nicea, según el cual las diaconisas "han de ser contadas totalmente entre los laicos, dado que no tienen ninguna clase de imposición de manos."

$Y$ así es como un afán perfectamente comprensible, que buscaba más santidad, mayor experiencia y menos aprovechamiento personal, abre la puerta a una evolución que irá configurando el ministerio eclesial como un sistema de separación respecto del pueblo, de carrera o ascenso personal y de rigido control. Si se me permile un juego de palabras algo forzado, la castidad llevó a la casta, el recorrido llevó a la carrera, y el rigor llevó a la rigidez. Las intenciones eran excelentes, pero la complejidad de la vida y de los hombres juega a veces malas pasadas. Y lo malo no es sólo eso, sino que, una vez separada de las buenas intenciones iniciales, una situación asł ha de recurrir a alguna justifiación térica para mantenerse.

\subsection{Justificación de esta evolución}

Y esta justificación teórica ya no recurrira simplemente al Antiguo Testamento, como veíamos que ocurria en el siglo III. Ahora, con la plena inculturación de la Iglesia en el platonismo, puede valerse incluso de una 
concepción metafísica del ser como "jerarquía," cuyo representante más conocido es el llamado "Pseudodionisio." Ya es expresivo en la obra de este autor ese escalonamiento de útulos por el que a una Jerarquía celeste le sigue otra obra, titulada Jerarquía Eclesiéstica. Y su lesis es clara: la jerarquía de la Iglesia refleja la jerarquía de los seres: "nuestra jerarquía es una función Insita en Dios mismo y en la ciencia divina y divinizante.

En una visión plotiniana de la realidad, todo está escalonado por su distancia respecto de Dios, la cual decide de su santidad y su dignidad, hasta llegar a la materia, que es lo más distante de Dios y, también, lo más indigno o malo. De acuerdo con ello, para nuestro autor "cada uno de los grados que viven próximos a Dios es más conforme a Dios que aquel que vive más lejos de El." más "altos" son "más capaces de recibir y transmitir la Luz de Dios." Por eso "la bienaventurada Tearchla (el poder de Dios) ha otogado a las sustancias racionales e inteligentes el don de la Jerarquía para asegurar su salud y su divinización." ${ }^{100} \mathrm{La}$ jerarquía es, prácticamente, lo que da contenido a la imagen y semejanza divinas del ser humano.

Para encontrar reflejado este carácter del ser en la estructura misma de la Iglesia, el Pseudodionisio considera como "sacerdotales" o clericales rodas las funciones eclesiales, desde el episcopado hasta el último orden menor. Por ello dispone que haya imposición de manos para todos ellos, sin distinguir demasiado entre lo que se llamará cheirotonia y cheirothesia, a las que ya hemos aludido. ${ }^{101}$ $Y$ diferencia los diversos órdenes entre sí, añadiendo una cantidad de ritos simbólicos para la ordenación de cada cual, pero de manera que el orden superior, aparte de su rito particular, ha de pasar por todos los ritos inferiores... Esta escala jerárquica de los ritos de ordenación reproduce la vida eclesial, donde ya hernos dicho que hay que pasar por todos los ordenes, uno tras otro, y comenzando por los más bajos. Como muy bien comenta Faivre, "a la absorción de las diferentes funciones corresponde la absorción de los ritos de ordenación. El paralelismo es perfecto, y el mecanismo jerárquico se ejerce en todos los dominios."102

Lo cuestionable de esta visión del Pseudodionisio se pone de relieve en la conclusión inapelable que saca de su sistema: si las cosas son así, se sigue que un ministro indigno, no santo, quedará automáticamente excluido de su rango de orden, lo cual, a su vez, implica la nulidad de los sacramentos que administra. Como es sabido, la Iglesia rechazó esta conclusión del Pseudodionisio, lo que parece implicar el rechazo del antecedente. Sin embargo, éste queda como tácita o ambientalmente asumido o, al menos, no cuestionado. De este modo, a los tres rasgos con que antes caracterizábamos a este siglo (separación. escalafón, control) se añade ahora un cuarto que los justifica intelectualmente: sacralización. 
Y con esto estamos ya, prácicamente, en el estado de cosas actual: ha nacido la hier-archía (el poder sagrado) en cuanto opuesto al laicado (o ser profano). Los siglos siguientes no harán más que pequeños retoques en esta esinuctura. Por ejemplo, y como ahora veremos, las luchas políticas y la falta de cultura harán que muchas veces el laico no sea propiamente el simple fiel, sino la poli-archía: el poder político, o el hombre con un poder no sagrado. Muchas de las aberraciones de la teoria de "las dos espadas" parecen menos aberrantes vistas desde aqui. Pero con ello se ve también cómo la forma interior de configuración de la Iglesia repercute en su forma exterior de presentarse ante el mundo.

\subsection{Nuevos problemas para ministerio y laicado}

Veíamos en la parte biblica con qué naturalidad habia la Iglesia naciente asumido y casi calcado la estructura de la comunidad judfa. De tener más tiempo, podría mostrarse igualmente con qué naturalidad va la Iglesia "liberada" por Constantino a tomar el modelo de organización política, econónica y administrativa del imperio. El obispo coincide con la figura de jefe de una comunidad ciudadana. A la integración de las ciudades en una provincia coresponderá ahora la aparición de la metrópoli, con un papel más importante para el obispo de la capital metropolitana, porque será el quien podrá convocar un concilio provincial y presidir (o confirmar) la ordenación de los obispos de la provincia, como sentala el canon 4 de Nicea A partir de Diocleciano, las provincias se agruparon en grandes territorios llamados "diơcesis," y entre los obispos de estas capitales diocesanas estarán algunos de los grandes patriarcas (Antioquía, Alejandría, etc.).

Esta rápida observación sólo pretende mostrar otra vez cómo la Iglesia no se estructura "desde el cielo," sino que existe una interacción entre la situación histórica y la configuración de la Iglesia, sin perjuicio de que esta intente ser comunidad "alternativa" en muchos puntos (por ejemplo, mediante la elección democrática de los obispos en un mundo de estructura imperial; o mediante la ordenación presbiteral de esclavos o el reconocimiento de la validez del matrimonio entre un liberto y una libre, que el imperio no reconocía como válido; etc., etc.). De todos modos, quizá tenga más importancia para nuestra reflexión el punto concreto de las relaciones con el emperador.

Por extraño que pueda parecernos hoy, es bastante claro que, en un primer momento, la figura del emperador "liberador de la Iglesia" casi fue asimilada al ministerio eclesial: Constantino fue llamado "obispo de fuera" y "decimotercer apostol," incluso antes de estar bautizado... Ello resultaba tanto más fácil cuanto que los emperadores segufan manteniendo aún el útulo pagano de pontifex maximus, y los obispos habian ido apropiándose el tílulo judfo de summus pontifex. Pero este espejismo linguíístico dará lugar a un brutal cesaropapismo que obligará a la Iglesia a moderar su entusiasmo y a ir reaccionando. 
No es cuestión de detallar la historia de esta reacción y de los conflictos que provocó, el más conocido de los cuales es el de Teodosio con san Ambrosio. Baste citar que hacia el año $375 \mathrm{cl}$ emperador Graciano renunciará al título de pontífice máximo. Esta separación resultará más clara en occidente; en oriente perduran el cesaropapismo y la intervención de los emperadores, durante el siglo $V$, en la convocatoria de los grandes concilios, a pesar de que un predecesor de ellos en el siglo IV (Valentiniano) ya había aprendido a responder a unos obispos de oriente que le pedian la convocación de un concilio: "yo soy un laico y no debo ocuparme de estas cosas." ${ }^{03}$ A pesar de lo cual, ya en el siglo V (iy en occidente!) el papa san Leon, a raíz de su positiva experiencia con el emperador en orden a la imposición del concilio de Calcedonia, todavla atribuirá al emperador la "inspiración del Espíritu Santo."1ot

Pero, a pesar de las inconsecuencias prácticas, estas escaramuzas servirán para establecer la ya mencionada precisión conceptual: ahora, el término "laico" se aplicará preferentemente no al simple fiel, sino al políicamente poderoso (el emperador y, más tarde, el señor feudal o el rey...). Esta decantación tácila del significado se extenderá prácticamente hasta Felipe IV de Francia. ${ }^{106}$ Pero en esta curiosa forma de distinguir (clero: poder sagrado; laico: poder político) esłá ya en germen toda la evolución ulterior: tanto el cesaropapismo de oriente como las luchas de las investiduras en occidente. En un caso, por la identificación en el poder; en el otro, por la lucha de poderes.

\section{En la pendiente clerical}

Una vez justificada en el siglo IV la evolución iniciada en el siglo III, vamos a verla continuarse durante el siglo $\mathrm{V}$. Y, además de continuarse, se intensificará en virtud de las nuevas y difíciles circunstancias que surgen en este siglo. Con ello se rebajarán también los elementos compensatorios de aquella evolución que habfamos visto en el siglo III ( $c f$. aparado 2.2.).

Estas nuevas circunstancias son de sobra conocidas: la caída del imperio de occidente y la subsiguiente crisis de la sociedad. La caida de Roma es -en negativo - un factor tan inaudito e impensable como lo había sido -en positivo- la conversión del imperio en el siglo anterior. Los escritos de la época asi lo reflejan. Pero ello no afecta a nuestro tema si no es porque -en la tremenda crisis de aquella sociedad, y en una Iglesia menos fuerte de voluntad que la de las persecuciones - van a surgir grandes dificultades de reclutamiento y de mantenimiento para los ministerios eclesiales. Ello contribuye a relajar la disciplina en vigor, y puede verse cómo los papas Inocencio I (401-417) y Zósimo, su sucesor, insisten en que se mantengan las estructuras de organización: no pueden ser admitidos los casados en segundas nupcias, los que han sido soldados... y los que no han pasado suficiente tiempo por los oficios "menores" hasta merecer la "recompensa" de la "eminente dignidad del presbiterado."106 
Se adivina la buena voluntad de estos propósitos; pero también será fácil percibir tanto su insuficiencia como sus contraindicaciones, tal como ahora vamos a ver.

\subsection{Aumento de los efectos negativos}

La carrera. Para empezar, la inevilable abreviación de los tiempos de permanencia, como modo de obtener más presbitteros, contribuye aún más a configurar los diversos ministerios como una "carrera" en la que los servicios "menores" son meros peldaños. Esto lo refuerza el hecho de que algunos de ellos se mantenían aun después de haber perdido su función con el paso del tiempo, de modo que se reduclan a ser meros compases de espera. ;Qué lejos estamos de lo que habla sido la pluralidad de los ministerios en las iglesias de Pablo!

Un ejemplo de nuestros dias puede ayudamos a comprender lo aberrante de semejante evolución, precisamente porque no es mas que última consecuencia lógica. Me refiero a aquel "privilegio" - del que yo mismo participe- que se concedió a los jesuilas para "no guardar los intersticios" prescritos en el paso de un orden a ouro: las "órdenes menores" se recibian todas en un mismo día, y las tres "mayores" (subdiaconado, diaconado y presbiterado) en tres dias sucesivos. En si mismo, se trata de un subterfugio sensato desde el punto de vista práctico (ipara qué entretenerse en realidades puramente nominales...!). Pero la visión teológica que lo sustenta es deplorable, porque entraña un reconocimiento de que la mayoría de los ministerios no son, en si mismos, nada. Cada uno de ellos es un mero "peldafio" para el siguiente.

$Y$, sin llegar a tales extremos, se percibe fácilmente, en el vuelco dado por este siglo, cómo lo que en el siglo IV había querido ser exigencia de experiencia se ha convertido en ascenso mecánico o en pura recompensa. Y por eso no será extrafio que papas de este siglo, como Celestino y san León, terminen asimilando el ministerio eclesial a la carrera militar. El ministerio es la militia divina y el paso por los diversos peldantos se justifica apelando a lo que ocurre... en el ejército. ${ }^{10}$

Estado, mís que función. Al haber ido dejando de ser "función" (o convertirse en algo puramente nominal), es práclicamente imposible que el ejercicio de un ministerio pueda constituir a nadie en miembro del "clero" (supuesta ahora la ampliación de esta palabra, que ya encontramos en el siglo IV). Por eso. entre este siglo y el siguiente se ira experimentando la necesidad de convertir a alguien en clérigo (una necesidad antano inconcebible, puesto que para eso se confiaban tareas y misiones reales). Y esta es la razón por la que aparece la "tonsura," como un umbral previo que no confla ninguna tarea, sino que simplemente constituye a alguien en "clérigo:" le hace "entrar en el clero." Como escribe, otra vez, Faivre: 
La existencia de la simple clericalura, sin orden preciso, muestra perfectamente que el clérigo ya no es el que cumple una función particular, sino el que forma parte de un estado privilegiado. ${ }^{108}$

En mi modesta opinión (y se trata de un juicio estructural, con independencia de la buena - y aun excelente- voluntad de las personas), este modo de concebir y de estructurar no es bueno para el ministerio eclesial, porque no responde al Nuevo Testamento y porque des-eclesializa el ministerio: pues los ministros no son ya los "hombres de la comunidad," sino que, en lodo caso, ellos son la comunidad, ellos son la Iglesia, porque ellos encaman "lo sagrado," y para ellos son los demás. ${ }^{109}$ Malo sería, pues, mantenerse en ese estado de cosas, que debe ser superado y que - como tal estado de cosas - es independiente de la vida santa o edificante de las personas concretas. Por poner un ejemplo de la época, el esfuerzo impulsado en su tiempo por san Agustín para que los presbíteros vivieran en comunidad con el obispo es en st mismo de enorme interés, y seguramente hizo un gran bien a muchas gentes; pero, metido en este contexto, probablemente contribuyó a afianzar este paso de la función al estado.

Y muy expresiva de este paso es, asimismo, la evolución que tiene lugar en lo referente a los monjes del desierto. Todavía en el siglo anterior, cuando aparece el monacato, los monjes no se ordenaban, porque no tenian una comunidad en la que ejercer una función. Debido a ello, tan sólo participaban en la eucaristía cuando se les presentaba alguna rara ocasión. En cambio, ahora -en el siglo $\mathrm{V}$ - es cada vez más frecuente la ordenación de los monjes que se ordenan "para si mismos." "110 Esta evolución es la que intentaba frenar el famoso canon 6 de Calcedonia, al que Schillebecka dio tanta importancia y volvió a poner sobre el tapete. ${ }^{11}$ Pero la verdad es que Calcedonia no consiguió frenar dicha evolución, y quizá no sólo por la dura inercia de las cosas, sino también porque las ordenaciones llamadas "absolutas" pueden tener otro sentido legitimo."12 En cualquier caso, el paso de la función al estado queda bien patente.

Sacralización extrema. Una vez convertido el ministerio en estado, entonces las ya inútiles "órdenes menores" van a recuperar una inesperada (y distorsionada) función: se convienten en una especie de "tierra de nadie" intermedia entre la jerarquía y el laico. Ya no son laicado, sino clero. Pero, al no estar aún obligados al celibato, esos clérigos contribuyen a separar a los laicos de "lo sagrado" y a la sacralización definitiva de los órdenes "mayores." Si sus funciones carecen de objeto, tampoco importa, porque el paso por ellas es como una preparación al celibato. De este modo, el celibato, que anteriormente habla tenido una fundamentación más servicial, pasa ahora a tener una fundamentación cotalmente culrual. ${ }^{113}$ Y se explica desde aqui: no es la entrega a la comunidad, sino la "dignidad del altar," la que lo exige. Asf se iró vinculando el celibato ministerial con el consejo que se da a los casados de que no tengan relaciones 
sexuales cuando han de comulgar. Y se irá generando una verdadera obsesión de que el laico (que de algún modo es el "impuro" o, al menos, el profano) "no

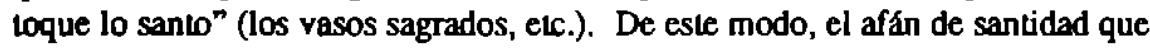
velamos en el siglo IV se mecaniza ahora: no es algo por lo que deba esforzarse el ministro, sino algo que ya tiene (o se lo supone) por su estado célibe, el cual sacraliza automáticamente. Y quedan ya lejos las razones que aducía el papa Siricio, lodavía a funales del siglo anterior, de que "estún absorbidos por las obligaciones constanles de sus trabajos."114

En rápida conclusión: de la etapa anterior se han intensificado los aspectos de "carrera," "sacralización" y (consiguiente) "separación." En cambio, se han reducido a casi puro nombre los aspectos de "experiencia" y "santidad."

Esto, naturalmente, podía funcionar en la oscura y dificil situación del siglo $\mathrm{V}$; pero es claro que en modo alguno puede funcionar en el siglo $\mathrm{XX}$.

\subsection{Disminución de las compensaciones positivas}

Al exponer el siglo III, indicábanos cớno el comienzo de mayor estructuración y rigidez del ministerio eclesial coexistía con una serie de espacios de libertad abiertos en la comunidad cristiana. Ahora hay que decir que esta situación persiste, pero bastante rebajada.

De todos modos, se mantiene la participación del fiel en la elección de su obispo. El propio papa san León es, en este punto, un defensor de la práctica eclesial, aun cuando ahora las condiciones materiales la hagan a veces más diff́cil, no sólo por las mayores dificultades de comunicación al paralizarse la vida cívica, sino también porque la aparición de los "metropolitanos" (de que hablábamos al estudiar el siglo IV) llevaba a algunos de ellos a reservarse el nombramiento de "sus" obispos. Y a uno de ellos le escribe san León: "no es licito a ningún metropolitano consagrar obispo a alguien por su cuenta, sin contar con el consentimiento del pueblo y del clero, sino que debe poner al frente de la Iglesia al que haya elegido toda la ciudad."115 $\mathrm{Y}$ a los argumentos de Cipriano sobre el origen divino de esta práctica afrade san León muchas veces algunas razones de elemental sentido común gobernante: "al que es conocido y aprobado se lo reclama con paz; al desconocido es preciso imponerlo por la fuerza; (...) el que ha de presidir a lodos, que sea elegido por todos," ya que lo contrario será siempre "materia de disensión." 116

Que estas frases no debian de ser pura teorí, lo comprobamos por el ejemplo de Inocencio I a comienzos de este siglo $\mathrm{V}$. Este papa creyó necesario intervenir para evitar que unas provincias eligiesen obispo a un hombre de pesima fama y que podfa ser un verdadero criminal. Ante situación tan límite, el papa interviene. Pero su intervención se limita a ser una recomendación a los obispos y al pueblo de aquella provincia en el sentido de que elijan a alguien mejor y más seguro. De ningín modo les impone él a un candidato, sino que vuelve a dejar la 
elección en manos de aquellas iglesias. ${ }^{117}$

Y algo de esto parece quedar todavía legislado en otra obra que es importante no tanto en sí misma, sino por el hecho de que influyó mucho en el pontifical romano y, a partir de ahí, en la legislación futura los llamados Statuta Ecclesiae Antiquae, obra también de este siglo V.

Los Statufa consagran ya legalmente la distinción clérigo-laico, así como los grados del clero (que pasarán, con muy pocos retoques, a la liturgia del Viernes Santo y a todos los siglos posteriores). También consagran definitivamente la concepción de que no hay verdadera "ordenación" más que a partir del diaconado, y que sólo el obispo tiene poder para ordenar. Estamos, como se ve, en lo que es la estrucluración eclesial que ha perdurado hasta hoy. Sin embargo, y a pesar de esta tendencia jerarquizadora, siguen citando a los laicos en el momento de abordar el nombramiento de obispos. Así, el canon 11, que pretende impedir que un obispo pase de una sede a otra (para evitar afanes de medrar y "camerismos"), legisla que, si en algún caso fuera mejor para el bien de la Iglesia semejante traslado, "se presente al sínodo un decreto para ser aprobado y firmado por clérigos y laicos."

Y si en este punto de la elección de obispos se adivinan aún esos espacios de libertad que había dejado el siglo III, en otros punlos, sin embargo, se percibe ya cómo algunos de esos ámbilos comienzan a tambalearse. Es el caso de la legitimidad o ilegitimidad de que un laico ensef̂e en presencia del clero. Sobre este punto encontramos en el siglo V dos posiciones contrapuestas. Los Statuta lo autorizan, en continuidad con la tradición antigua, si bien establecen la necesidad de que los tales clérigos den su autorización." ${ }^{119}$ En cambio, el papa san León, en una carta al obispo de Antioquía, niega tal derecho: la predicación es competencia exclusiva del "orden sacerdotal," y en la Iglesia, como cuerpo de Cristo, conviene que cada oficio lo desempene la persona idonea, y que los miembros inferiores no ejerzan tareas propias de los superiores. Es interesante notar cómo la imagen paulina del "cuerpo," que pretendía ser más igualitaria en la diversidad, ha sido jerarquizada en este texto. ${ }^{120}$

La distinción entre clérigo y laico ha quedado totalmente consumada. Y para uno y otro concepto se adivina una trayectoria que puede trazarse, más o menos. del siguiente modo:

-el concepto de "clero," de hacer referencia al sacerdocio universal de los cristianos, ha pasado a referirse exclusivamente a la trlada obispo-presbfterodif́cono, y luego a todos los "insurados;"

-el concepto de "laico," al comienzo, no designaba a nadie; luego designó a los más cercanos a la dedicación del clero a la Iglesia; más tarde designaría preferentemente al poder político; y, finalmente, pasó a designar a todos los noclérigos. 
Lo que queda son ya puros retoques de detalle en esta evolución clerical, que, de hocho, ya está prácticamente ultimada.

\section{Ultimos retoques a la clericalización del ministerio}

Con el siglo VI queda clausurado, en mi opinión, todo el proceso que venimos describiendo. Este siglo ya no aportará más que los últimos retoques. Y la evolución posterior no hará sino introducir diversas correcciones exigidas por el mantenimiento (o por accidentes imprevistos) de aquel edificio en el que todavía habitamos nosotros.

Podemos dividir nuesura exposición en dos partes. La primera, en realidad, es una continuación, siguiendo la inercia de la historia, de lo que hemos visto que fue el siglo anterior. Con respecto a la segunda, podríamos decir que lo deja todo "oficialmente" consagrado y clausurado con la importante reorganización de $\mathbf{l a}$ Iglesia y del papado que lleva a cabo, a finales de este siglo, uno de los más grandes papas de la historia de la Iglesia: Gregorio I.

\subsection{De ministerios eclesiales a personajes consagrados}

En continuidad con el siglo anterior, también en el siglo VI siguen disminuyendo las vocaciones, lo cual obliga por lin al papa Gelasio (492-496) a aceptar que se acorten cada vez más los tiempos de permanencia en cada ministerio, con el objeto de facilitar el "reclutamiento." A ello se aftade otro factor nuevo, como es el nacimiento ( $y$ desarrollo) de una burocracia papal, con la consiguiente aparición de funciones administrativas (v.gr., notarios, etc.) desconocidas hasta entonces.

La conjunción de ambos factores hará que se intensifique la primacía del principio de "antigivedad" sobre el de "aptitud," típica de todo sistema jerárquico estricto. Ironizando un poco, podría decirse que también en la Iglesia parece cobrar vigencia el famoso "principio de Peter," igualmente úpico de dichos sistemas. Como consecuencia de ello, la imagen sociológica del ministerio ha experimentado un cambio: de expresar una relación entre una función determinada y la comunidad eclesial, pasa ahora a expresar la relación de una función con un individuo particular. El ministerio eclesial no define primariamente una determinada tarea o un servicio comunitario (de ensefhanza, de asistencia, de liderazgo, etc.), sino que expresa primariamente el estado de una persona. De este modo se verifica lo que indica nuestro subtitulo: más que "cumplir funciones," se "constituyen personajes sagrados."

\section{De clérigos a eclesiásticos}

Esta etapa, como acabamos de decir, conluye a finales de siglo con san Gregorio Magno (590-604) y su importante reorganización del papado y de la 
Iglesia. Pero de esa reorganización podriamos sefialar dos aspectos: uno más negativo, que consagra toda la evolución seguida, y otro más positivo, que quizá pone de relieve cierta conciencia de los elementos negalivos de dicha evolución.

Gregorio I decide ahora que todas las nuevas funciones administrativas que van apareciendo en la curia papal sean revestidas con los tútulos de dignidad de aquellos ministerios u órdenes antiguos que ya no tienen función litúrgica ni comunitaria: las ordenes menores. De este modo sucede que, para ejercer una función meramente administrativa en la curia papal, hay que ser clérigo, hay que estar tonsurado. Consiguientemente, estas funciones ya no puede desempenarlas un simple laico. Asl es como, imperceptiblemente, los "servidores de la Iglesia" pasan a ser servidores del aparato o de la instilución, más que de la comunidad. Ellos serán los "eclesiásticos," término que cubre, más o menos, el mismo campo semántico que el de "clérigos," y que designa a quienes han recibido la tonsura.

Pero la creatividad de Gregorio I va más allá de lo puramente organizativo. Este papa sabe percibir que la nueva siluación de Europa supone para la Iglesia un desallo misionero: los pueblos bárbaros han de ser cristianizados no ya cuando aterrizan por las ciudades del antiguo imperio, sino en sus mismas tierras de origen. Son conocidos tanto los envíos de misioneros por parte de este papa (v.gr., el de san Agustín a Inglaterra) como las sensatas y cristianas instrucciones para llevar a cabo la evangelización de un modo inculturador y pacffico, no impositivo y violento: no derribar templos dedicados a otros dioses; no destruir, sino más bien transformar; no invalidar los usos y costumbres sociales de fiestas, aniversarios, etc., sino llevarlos más bien a "conocer el gozo interior:" porque "no se puede quitar todo de un solo golpe a almas frágiles," ni "se sube una montaña a saltos, sino con pasos lentos." 121 Todo ello devuelve al ministerio aposiólico su carácter de envio y de misión eclesial (como en Hch 13) y restituye a muchos eclesiásticos el sentido apostólico de su ministerio, si bien no siempre llega a recuperar para esa misión su carácter oficial de ministerio, debido a la siluación ya burocratizada y esclerotizada del ministerio "olicial."

Pero al menos, como hemos dicho, este importante paso creativo ayuda a cobrar conciencia de algo que ya estaba tácitamente vigente en la nueva estructuración de los ministerios: que los ministerios eclesiales, dominados por la necesidad de "organizar la Iglesia," hablan dejado de ser misioneros. Desde la evolución que habia comenzado hacia el siglo III, los obispos, vueltos cada vez más hacia el interior de la Iglesia y hacia el cullo, se hablan ido haciendo cada vez menos propagadores del evangelio y más distantes de la figura de los apóstoles. Y aunque esta afirmación no haría justicia a los siglos IV y V, dada la gran calidad teológica de tantos obispos y padres de la Iglesia que constituyo su legílima manera de ejercer el aposiolado y el ministerio, no obstante, como subraya de nuevo A. Faivre, ya entones iba siendo un dato evidente que la casi 
totalidad de las conversiones no las lograban los detentadores del ministerio eclesial, sino los excluidos de el: los laicos (el comeciante que viajaba; el esclavo que era vendido y trasladado; el militar que era hecho prisionero en un pais lejano....). ${ }^{12}$ Desde entonces ha venido ocurriendo en la Iglesia algo realmente curioso: los hombres que más oficialmente tienen encomendado el encargo de "ir por lodo el mundo y anunciar el evangelio a todas las gentes" son precisamente los que menos anuncian el evangelio, porque orras mil ocupaciones y preocupaciones administrativas se los impiden. La comunidad se sigue definiendo cono "misionera" pero sus responsables últimos ya no lo son, e incluso en ocasiones están impreparados para ello, porque conocen mucho mejor el "derecho" de la Iglesia que el significado humano del evangelio. Y también se los impide una notable falta de contactos humanos aptos para ese anuncio. porque sus círculos más habituales de convivencia y su audiencia más inmediata están constituidos casi totalmente por las "ovejas" supuestamente más fieles, que casi parecen las que menos necesidad tienen de pastor (a veces incluso alejadas ellas mismas de la realidad de su sociedad y de los gozos, esperanzas, angustias y preocupaciones de los hombres de su época). $O$, en todo caso, su trato con "los de fuera" se reducirá a los contactos con poderes políticos, con los cuales hay que "negociar" en determinadas simaciones o encontrarse en algunos actos "públicos"...

En realidad, nos hallamos aqul muy lejos de la imagen que refleja la vida de Jesús, lo cual debería ser molivo de preocupación (y criterio de renovación) para todos los ministros de la Iglesia de hoy. Serfa muy interesante que algún organismo especializado en estadística o en investigación sociologica pudiera realizar una encuesta entre todos los obipos del "primer mundo" y les planteara, por ejemplo, estas dos cosas: cuántos increyentes 0 , al menos, no-católicos hay en su círculo de relaciones más cercano; y si hay algunos, ¿es ello fruto de alguna relación personal o, simplemente, del encuentro ocasional con poderes políticos con los que se ha tenido que tratar o negociar?

No decimos esto en tono de ironia, sino, en todo caso, con bastante angustia. ${ }^{123}$ Pero lo expuesto es suficiente para mostrar cómo queda prácticamente clausurada la evolución que hemos tratado de exponer, y que conduce a una extraño clericalización del ministerio eclesial, el cual habla nacido tratando precisamente de distanciarse con claridad de todo rasgo clerical. ${ }^{124}$

\section{A modo de apéndice}

Ya en la alta edad media -con la pérdida del laún, y tras la reforma carolingia-, sucederá que la vinculación del ministerio al culto -que ya conocemos - irá a dar en una pérdida de la Eucaristía como Cena del Seffor y en una concepción de la Misa como espectáculo maravilloso en el que importa más contemplar (desde la lejanfa) que participar. Raras veces se comulga en ella: sólo se asiste en calidad de "oyente" ("oír" misa). 
Pero, además a lo largo de la edad media se produce una decadencia o comupción del estado de cosas descrito en todo este apartado, cuando el ministerio eclesial asume también poderes polfícos y económicos. Estos últimos - los "beneficios", etc.- tentarán además a los papas, que acabarán queriendo controlarlos todos. Asf, se puede decir - por más anticristiano que suene- que "ministerio" se ha convertido en igual a "beneficio."

Son de sobra conocidos los detalles de esa corrupción. Digamos tan sólo, en una rapidísima pincelada, que esta corrupción suele tener un doble rostro: en el episcopado y en los beneficiados, la corrupción del poder o corrupción de la curia (riqueza, simonta, inmoralidad económica, alejamiento de los fieles...); y en el presbiterado (al menos en el llamado "bajo clero"), la corrupión de la incuria (analfabetismo, falta de la formación más elemental, superstición, concubinato habitual, etc.).

También son conocidas las incontables voces que, durante toda la edad media, reclamaron la reforma de la Iglesia. No sólo voces heterodoxas o empujadas a la heterodoxia por la incomprensión de la jerarquía (valdenses, husitas..), sino también voces de santos y de eclesiásticos fieles e incomprendidos (Bemardo, Catalina de Siena, elc.). ${ }^{18}$ A veces se intentó compensar esta degeneración mediante la asimilación (o la huida) del ministerio a la vida religiosa. Pero otras veces la misma vida religiosa se vio también contaminada por la necesidad de reforma. Ejemplo de lo primero lo tenemos en las incontables asociaciones de clérigos que, bajo la regla de san Agustín, pululan por Europa a lo largo del siglo XI, y que son quizás el intento más importante para buscar una vida como la religiosa, pero no en "la paz del campo," sino entre las complicaciones de la ciudad.

Otro ejemplo más extremo lo tenemos en lo que ocurre con el fenómeno de los eremitas, que, a pesar de su huida del mundo, se convirtieron en "padres espirituales" de muchas gentes, conforme la mundanización del clero iba haciendo imposible la función "médica" (o mistagogica) del ministerio. Recordemos a Roberto de Arbrissel, Bemardo de Tiron, Henri de Lausanne y tantos otros, casi lodos ellos clérigos ordenados, pero que -ipor razones evangélicas! - hablan abandonado el ejercicio oficial de su ministerio y escandalizaban a la sociedad con la miseria de su aspecto ffsico (pauper ego, mendicus ego). Muchos de estos hombres fueron afamados "directores de almas" constantemente visitados. Curiosamente, el eremitismo encarna entonces, a un mismo tiempo, la función de protesta (a veces incendiaria) contra el escándalo de las riquezas del clero, y la función de "dirección espiritual" (o mistagógica), que ahora no se dirige sólo a nobles, sino también a prostitutas, leprosos y demás marginados: una de las grandes reivindicaciones de aquellos eremitas era que no había necesidad de "alta cuna" ni de buena educación para alcanzar la santidad. $Y$, curiosamente, del mismo modo que hoy tendemos a presentar el celibato como forma de pobreza (autoempobrecimiento, etc.) a la hora de fundamentarto 
teológicamente, en aquella época —an obsesionada por la "pureza" - se presentaba más bien la pobreza (o el empobrecimiento) como forma de pureza.

En cualquier caso, esta pincelada es útil para notar una cosa: algo tan caracteristico del ministerio como es la ayuda espiritual se ejerce ahora al margen de él y como ajeno a él. Y, sin llegar a tales extremos, la negativa de un hombre como Francisco de Asís a ordenarse de presbítero y el voto que Ignacio de Loyola impone a los suyos de no aceptar obispados (a pesar de que Ignacio era hombre más dado a la negociación y a los caminos del posibilismo) son en si mismos - y más allá de las intenciones de ambos personajessímbolos muy hirientes de que "algo no acaba de ir definitivamente" en el ministerio eclesial.

Pero, si hemos evocado rápidamente esta dolorosa etapa, era para poder antadir una palabra sobre la llamada "reforma católica" y lo que ella pudo suponer para nuestro tema. Trento realizó una reforma de una seriedad y unas dimensiones literalmente impensables. Pero hay que reconocer, además, que la realizó demasiado tarde (como tantas veces le ocure a la Iglesia a lo largo de su historia). Y por eso fue una reforma ya polémica, en la cual, además de reformar, había que defenderse de la ruptura y los ataques luteranos. La polémica y la autodefensa dieron a la reforma tridentina una cierta parcialidad o unilateralidad: fue mucho más una reforma de costumbres que de concepciones. Por eso apuntó a recuperar más la moralidad que la "cristiandad" del ministerio tal como la testifica el Nuevo Testament. Porque éste se había convertido para entonces en el campo de batalia de los protestantes, y el instinto de defensa típico de todas las polémicas sugerla que era peligoso "jugar en campo contrario."”x

Todo ello nos permile comprender por qué la reforma tridentina, como único recurso teológico reformador (y para combatir lo que Lutero quería recuperar del Nuevo Testamento), reforzará la ontologización y cosificación del ministerio, el cual ya no estará vinculado inmediatamente a la comunidad, sino a la Eucaristra (ahora separada también ella de la comunidad y convertida tantas veces en "misa privada"); y tampoco se definirá por el apostolado y la palabra, sino más bien por el culto. Así, "los seminarios contribuyeron a formar el tipo de sacerdote que se ha mantenido hasta hoy: un hombre separado del mundo por su hábito y género de vida, que celebra la misa todos los días, reza su breviario y se muestra consciente de sus deberes pastorales." ${ }^{\text {"12 }}$

Pues bien, dentro de este marco ambientador me parece interesante decir una palabra sobre la clasificación que propone J. María Rambla de los tres modos de entender el ministerio en la época postridentina. Con esta rápida observación concluiremos este apéndice. ${ }^{12 a}$

Las tres maneras de entender el ministerio que vamos a exponer quieren ser, todas ellas, reformadoras. Y Rambla cree que se encarnan en estas tres tendencias. 
Una, más monástica, cuyo lema, según nuestro autor, podría ser. "santidad Y ministerio". Continúa la imagen del ministerio de Clicjtovec (a la que Schillebeeckx da tanta importancia, como se recordara), ${ }^{\text {io }}$ y la encaman preferentemente los llamados "clérigos regulares" (teatinos, barnabitas, somascos...), o presbíleros que vivían sub canone.

Otra, más ascélica, está representada por la escuela francesa (Bérulle, Olier, san Juan Eudes...), y su lema podría formularse - -según nuestro autorcomo "santidad PARA el ministerio." Esta línea sería la que mejor encarnaria aquella formula del alter Christus cuya unilateralidad mostrábamos en nuestra primera parte. Para ella, el origen del sacerdocio sería la necesidad de dar a Dios una adoración digna de él. Y eso sólo le es posible al hombre por la encarnación, que constituye el sacerdocio de Cristo. (Lo cual no es en sí mismo incorrecto; pero ahora se trata de una encarnación que abstrae de - y permanece ajena ala vida humana y el destino histórico del Jesús real.)

Finalmente, otra más misionera y que Rambla caracteriza como "santidad EN el ministerio," y en un ministerio necesariamente pluralista. Su lema seria: "ayudar a las almas." Y para ello irán postulando modos de vida que los hacen entrar en conflicto con los clérigos regulares y que se concretan en aspectos tales como: movilidad, pluralidad de tareas (lo cual da entrada a la acción social y a todas las discusiones ulteriores sobre si ésta "pertenece o no" al ministerio, y que duran hasta hoy), comunidad no local, libertad frente a muchas prácticas establecidas (referentes, v.gr., a liturgia, hábitos, etc.). Y, en general, la búsqueda de un ministerio más relacional que puramente cultual. Según nuestro autor, en este último punto habría que colocar a Ignacio de Loyola, y éste sería uno de los rasgos más importantes de su significado histórico: acceder al ministerio, pero rompiendo los moldes que lo configuraban en su época. Sea como fuere a este respeito (que es algo que ya debatirán los historiadores), lo que sí resulta claro para nosotros y para nuestra reflexión es que sólo esta última forma parece conservar vigencia y posibilidades significantes para nuestro mundo de hoy. Esta es la razón por la que me ha parecido útil afladir este apéndice.

\section{Notas}

63. A. Faivre, Les laïss aux origines de l'Eglise (París 1984), p. 57. Recojo en muchos momentos las informaciones de este autor, así como de su anterior estudio: Naissance d' une hierrarchie (Paris 1977).

64. Las defersas nacieron por razones apologéticas, para exonerar a las eucarisúas cristianas de las acusaciones paganas: que eran orgías incestuosas donde se sacrificaban niños, etc., etc. (Como ejemplo, $c f$. Justino, Apologia 1, 65-67). Las descripciones miran más bien a la vida interior de la comunidad (ejemplo: Didaché, cap. 9). 
65. Y que, por lo demás, es Kogico, dada la finalidad más apologética que jurfdica de estos textos. Sobre Ireneo, $c f$. Adv. Haer IV,17,5; IV,18,4-5; V,2,2-3. El problema teológico de la eucaristía, para Ireneo, no es determinar quién la celebra (él habla siempre genéricamente de "la Iglesia"), sino mostrar que la eucarista no se ofrece porque Dios sea "concupiscente o deseoso de lo ajeno," y que la transformación eucarística abre la posibilidad de la transformación de nuestros cuerpos en la resurreccion.

66. Smirn. VII, 1. Tampoco se indica aquí si se trata de una presidencia eucarística encomendada como estado habitual o únicamente ad aswn. En el texto de Ignacio, lo primero sólo puede afirmarse claramente del obispo.

67. Cf. Adv. Haer. I, 13,2.

68. No es posible interpretar las palabras de Justino (I.67) - "el presidente eleva plegarias ose dynamis autô "- como si aludieran al poder de la ordenación sacerdotal. J. Solano reconoce expresamente que fuerza la traducción del texto para hacerle decir eso: "la explicación de esta frase es discutida. Damos una traducción que favorece la interpretación de que se refiere aqul san Justino al poder sacramental que debía tener el presidente de la reunión para consagrar el cuerpo del Serior" (Tecos eucaristicos prinitivos [Madrid 1952], p. 63; subrayado del autor). A la lar$\mathrm{ga}$, semejantes procedimientos -en un texto que se reconoce expresamente como disculido- no benefician, sino que dañan a la Iglesia. Porque sólo la verded hace libres.

69. Cf., v.gr., Justino, Dílogo ... 116, 3.

70. Naissare ... (cil), p. 167.

71. Que ese texto egipcio ya conocido era la T.A., atribuida a Hipolito y que se cteĺa perdida, es la conclusión a la que llegaron por separedo E. Schwarta y R. H. Connolly. Sigo en esto la introducción de B. Bone a la 2a. edición de la T.A., en Sources Chrétiennes (1984).

72. De exhortatione castilasis 7,3 (lo citaremos en la nota 80).

73. Aunque no necesariamente desde una perspectiva cristiana pues "las cosas del Señor" no son propiamente las del culto, sino las de la vida de los hemmanos. Por eso, en el texto, no las contrapongo a las cosas "de la tierra," sino a las cosas "propias."

74. Ese era el ideal de Clemente Alejandrino, de Tertuliano, etc., que Orígenes constatará como cada vez más lejano. Cf. A. Faivre, Les laïes ... (cit.), pp. 160-161.

75. Aunque poco a poco, por la inercia de "lo temporal" esa colaboración irá quedando reducida a asegurar la subsistencia material de los ministros eucarlsticos.

76. Cf. A. Faivre, Naissance ... (cit.), p. 67. No hace falta ponderer le enome importancia del ministerio de "lector" en una época en la que muy pocos saben leer y en la que la lectura oral es así la única fuente de contacto y transmisión de la Palabra.

77. Cf. T. A., 10.

78. Cf. A. Faivre, Les laics ..., (cit.), pp. 130-131 y 94. La tipologfa veterotestamentaria no es del todo inocente, por cuanto lleva implícila la consecuencia de poder "vivir del altar."

79. Y el argumento debe valer tambien a la inversa. Hace años, hubo uma famosa pelfcula (Le Defroque) que pretendfa que un cura apóstala y no-creyente podria 
consagrar las especies por el solo hecho de que un día le habían sido impuestas las manos, y ahora él repetía mecánicamente unas palabras (que entones eran latinas): aquel Renegado eta ligura opuesta a la del Confesor de la T. A., y nos lleva otra vez a la imposibilidad de una mera apostolicidad formal. Por decirlo en terminología clásica y segura: allí faltaría la intención de "hacer lo que hace la Iglesia" por cuanto la mínima intención de la Iglesia es seguir a Jesús. Por tanto, no existía consagración real de las especies, y la presunta fuerza dramática de El Renegado era más bien melodramárica.

80. De exhortatione castisatis 7, 3 (Ed. Sources Chrétiennes, p. 92). La segunda frase dice literalmente: differentiom inter ordinem et plebem constifuit Ecclesiae autorilas, donde ordo parece traducir el griego kleros.

81. Obras de san Cipriano. Carta 75, 10 (Ed. BAC, pp. 712-713). Algo parecido poctría testificarse también por lo que toca al perdón de los pecados, tema en el que, igualmente, hay algunos datos que ofrecen dificultad. Igracio de Loyola cuenta en su Awobiografta que, antes de entrar en el combate en el cual resultaría herido, se confesó con otro soldado. El texto no refleja una mera superstición particular, sino una cierta práctica eclesial, como lo muestra esta recomendación de Canfranc, arzobispo de Canterbury, ya en el siglo XI: "si no encuentras a un clérigo, de cualquier grado que sea, para confesarte, escoge a un hombre honrado donde te encuentres... Un hombre puro puede purificar a un hombre culpable en ausencia de codo clérigo" (citado por J. Comby, Para leer la historia de la Iglesia [Ed. Verbo Divino, Estella 1985]. I, p. 153). Más aún: en el diario particular que el papa Pío II llevó durante su pontificado, cuenta con toda naturalidad cómo el rey Enrique de Inglaterra antes de una de las batallas de la guerra de los Cien Años, había exhortado a sus soldados a que "se confesaran los pecados unos con otros" (alter alteri pecata confiteamur) para recabar la ayuda de Dios (cf. Pü II, commentarii rerum memorabilium quae temporibus suis contingerunt [Ed. A. Van Heck, Città del Vaticano 1984], I, p. 385).

82. Obras de san Cipriano (cit), p. 714.

83. Lo dicho aquí y en la nota 79 no obsta para que haya otros casos en los que esa “intención de la Iglesia" pueda ser más compleja y, por tanto, más difícil de precisar con toda exactitud (recuérdese lo dicho en la nota 39). K. Rehner llega incluso a decir, en relación a la ordenación sacerdotal, que esa intención de la Iglesia puede ser veriable, según las Epocas (cf. Escritos de Teologla VI [Taurus, Madrid 1969], p. 394). Pero, a pesar de estas dificultades, este principio tan clásico puede convertirse en un buen camino hermenéutico para la solución de los problemas extremos que hernos ido encontrando.

84. Como pasaria hoy si un obispo agumentara con alguna historia en la que se diera tranquilamente por sentado que una mujer había dicho misa y, con ello, lo había engaũado a él o a su clero.

85. "Hay que cumplir y mantener con diligencia la enseñanza divina y práctica apostolica que se observa entre nosotros y en casi todes las provincias: que, para celebrar las ordenaciones rectarnente, alli donde haya que ordenar a un obispo junto al pueblo se réfman con el pueblo todos los obispos próximos de la provincia y se elija al obispo ance el pueblo, que conoce la vida y la conducta de cada uno, por convivir y tratar con el"... E pueblo debe apartarse de los obispos pecadores, dado que tiene "poder para elegir obispos dignos y recusar a los indignos." Por eso vamos que 
"viene de origen divino el elegir al obispo en presencia del pueblo, para que todos lo aprueben" (Carta $67,5,1 ; 3,2$ y 4,1 [Ed. BAC, pp.635 y 634]). Lo mismo afirma Cipriano de símismo (Carta 59,6,1 [Ed. BAC, p. 570] y del obispo de Roma, Comelio, para refutar así las pretensiones de Novaciano: "ha sido elegido por el juicio de Dios y de su Cristo, por testimonio de todos los clérigos, por el voto del pueblo que estuvo alli presente, por la comunidad de obispos venerables y de varones buenos" (Carta 55, 8,4 [Ed. BAC, p. 526]).

86. "Desde el principio de mi episcopado determiné no tomar ninguna resolución por mi cuenth, sin vuestro consejo y el consentimiento de mi pueblo" (Carta 14,1 [Ed BAC. p. 412]). Las razones de este proceder las aduce también el obispo de Cartago: "serla muy agobiante para mí y muy mal visto por mí lomar yo solo una decisión... (que afecta a muchos) y no podría tener gran fuerza lo que no parecieta contar con el consentimiento de muehos" (Carta 30,6 [Ed. BAC, p. 452]). O bien: "sobre este punto no creo poder dar juicio por mi parte solamente, puesto que todavía están ausentes muchos del clero... y ha de estudiarse y aquilatarse el caso de cada uno con codo detalle, no sólo con mis colegas, sino con todo el pueblo. Pues hay que estudiar con moderación y equilibrio lo que podrla crear un precedente en el futuro..." (Carta 34, 1 [Ed. BAC, pp. 467-468]; subrayados míos).

87. Hay temperamentos a los que es mucho más fácil ser héroes en un momento o tiempo breve que ser pacientes o respetuosos en una conducta larga La vida se encarga de mostrar esto de mil maneras.

88. Por eso varias de sus cartas van dirigidas "a los presbiteros, diáconos y pueblo."

89. Didaskalla de los Apostoles III, 12, 1-3. Es curiosa en esta obra la preocupación por la moral sexual del clero, hasta el punto de que a veces parece que el autor hace consistir en ello la diferencia entre clérigos y laicos (a pesar de que acepta al obispo casado: $c f$. I, 2, 1-2). Y, sin embargo, exhorta sobre todo al obispo a ser misericordioso como Dios con los pecadores, amenazándolo si convierte su propia virtud en un motivo para negar el perdón y la misericordia a los demás.

90. Piénsese, simplemente, en la gran confusión que cré a la Iglesia el problema de la reconciliación de los cismáricos o la llamada cuestión de los lapsi (apostatas durante la persacución de Decio), que fue una de las cruces de san Cipriano y uno de los motivos del cisma de Felicísimo. El pueblo - por una reacción comprensible de defensa propia pero no demasiado cristiana se obstinaba en no perdonar a los que hablan apostatado. Cipriano y otros muchos obispos propugnaban una reconciliación con penitencia, pero querian para ello convencer al pueblo y no imponerlo por si solos, de acuerdo a lo dicho en la nota 86. En este contexto, Cipriano se lamenta en más de una ocasión: "si pudieras intervenir conmigo, hemano querido, cuando estos desviados vuelven del cisms, verias qué trabsjo me cuesta convencer de paciencia a nuestros hermanos y calmar su indignación para que consientan en recibir $y$ remediar a los culpables" (Carla 59, 15, 3 [Ed. BAC, p. 581]). Cipriano reonocer incluso que en slgune ocasión fue él quien se equivoco, y que aquellos cismáticos no volvían amepentidos a la Iglesia.. Pues bier. en este contexto, una sarie de "confescres" imprudentes, por af́n de protagonismo o de vanidad, se arrogaban el poder de interceder o de reconciliar sin mús, sin penitencia alguna. ¿Cómo pudo no desintegrarse una comunided en tal situnción (ten "verosímil," por otra parte, desde el punto de vista humano), sin unos minimos de estructuración de control y de auroridad? Todo eato es innegable, amque a la vez se puedn añadir que no todas las 
épocas son épocas de persecución en la historia de la Iglesia

91. Asociación Juan XXII, Teología y Magisterio (Sigueme, Salarnana 1987), p. 110. (El capítulo de J. Rius se intiula "Diversificaciones de ministerios en el área sirohelenista: de Ignacio de Antioquía a las Constituciones Apostólicas," pp. 75113).

92. "El obispo en la Iglesia," en Escritos de Teologia VI (cil), p. 390.

93. Ainsi les lä̈cs, appartenant an peuple des prêtres, deviendront-ils, très vite, le peuple des prêtres (Les bïcs ... [cil]. p. 94). Juego de palabras muy expresivo y que pierde fuerza al ser traducido al castellano.

94. Leyendo textos de la época, no se puede evitar la comparación con algunas cosas vistas y oídas en 1979, tras el triunfo sandinista en Nicaragua, o tras cualquier otro de los momenlos victoriosos de la historia humana, que siempre hacen concebir esperanzas desorbitadas para el futuro que resta.

95. Cosa que, no obstante, se intent6, por ejemplo, en España y en el concilio de Nicea, donde, según nos cuenta el historiador Sóctates, la intervención del obispo de la Alta Tebaida, Pafnucio -que era célibe y tenía gran fama de santidad-, evitó que se convirtiera en ley (cf. Historia eclesiástica I, 11).

96. F. G. Alberigo, Conciliorum decumenicorum Decreta (Freiburg 1962), pp. 13-14. Y permítanseme un par de observaciones sobre este dectet:

a) Conviene notar la nitidez con que se establece que el presbitero tiene la polestas offerendi, y el díácono no; lo cual es exactamente el estado de cosas actual. Si los historiadores muestran que ese estado de cosas es datable ya un siglo antes, entonces cobraŕa pleno valor el tex to sobre la incorporación automática de los "confesores" al presbiterado (T.A. 9) que hemos citado antes y al que ponfamos ciertas reservas. b) Se adivina ahora una asimilación del discono a lo que podría ser hoy el "secretario particular" del obispo. Ello dería lugar, por parte de los dí́conos, a la clásica presunción de todos los sectetarios, porque tienen más fácil acceso y más posibilidades para una persuasión personal, etc., etc.

97. El canon 16 de Nicea trata de evilar que los presbíteros de una Iglesia particular se cambien a otra por su cuenta, o que los que no quiso ordenar el obispo de un lugar vayen a ordenarse a otro. Se adivina aquí no sólo una cierta idea de la "ordenación absoluca" con más de un siglo de antelación sobre el canon 6 de Caledonia (al cual Schillebeekx da tanta importincia en su libo), sino una actuación que evoca la que hernos vivido recientemente con el seminario de Toledo, adonde acudían, esnudiaban y eran ordenados sujetos rechazados en los seminarios de sus respectivas dibcesis de origen. Estos problemas son de codas las Epocas, porque la pluralided y las diferencias no son exclusivas de nuestro tiempo. Hoy, con la movilidad de la vida, probablemente dejan de aparecer como problemas tales diferencias; pero a la Iglesia le sigue costando admitir un pluralismo serio, sobre todo por el "ala izquierda" Y el problema de las "ordenaciones absolutas" no estí aún resuelw de una manera clara y que loge integrer suficientemente el diffil binomio de lo local y lo universal.

98. De ecclesiastica hierarchia L 1 (PG 3,369).

99. Carta VIII: PG 3, 1092 B. Ciln en A. Faivre, Naissance ... (cit.), p. 179.

100. De ecclesiastia hierarchia L, IV (PG 3, 376 B).

101. Lo que importa al Pseudodionisio en el terna de la imposición de manos no es ya la transonisión de una misión, sino el hecho de que expresa la sunisión a Dios. "Este 
riv designa la protección de Dios... y les enseña a cumplir todas las funciones sacerdolales como bajo les órdenes de Dios, considerándole como su Superior en codos los actos de su vida" (De ecclesiastia hierarchia V, II, 263 [PG 3, 512 A]).

102. Naissance ... (cit), p. 178.

103. Ciţ, en A. Faivie, Les laìrs ... (cit.), p. 171.

104. Vérse, sobre este punto, A. Grillemeier, Jesus der Chrisıus in Glauben der Kirche II (Freiburg 1986), pp. 164-165, más el artículo de K.Voigt allí cilado sobre la "infalibilidad" del emperador.

105. Como ya he insinuado, esto hace más inteligibles los lenguajes de la Bula Clericis laicos (de Bonifacio VIII) y del documento de respuesta (Ansequam essent clerici) de los teólogos del rey francés.

106. Cf. A. Faivre, Naissance ... (cit), pp. 321-328.

107. Ibid., pp. 330-331: stipendium, militare in castris dominicis, aggregari divinae militiae...

108. Ibid, p. 360.

109. Buena prueba de ello es el significado social que ha adquirido la palabra "iglesia" y la imposibilidad práctica de entender por esta palabra otra cosa que no sea la "jerarquí" (o, a veces, el papa solo). Todo el mundo reconocería que, si ese modo de hablar se erigiese tébricamente en legítimo, seria herético, puesto que la Iglesia no son soblo los jeracas. Pero, en la préctica, es esí como funciona el lenguaje.

110. Cf. A Faivre, Les laīes ..., pp. 226 y 222.

111. Cf. El minisierio eclesial ... (cit. en la nola 15).

112. Sentido que no es el de "ordenación para sí mismo," sino el de "entrada en el colegio" (de obispos o de presbiteros) y en las responsabilidades del mismo, ya que el ministerio eclesiástico, derivado del apostoledo, es inúnsecamente colegial. Pero hay que reconocer que esto implica una verdadera asunción de sareas ministeriales de la comunided y, en este sentido, ya no es ordenación "absoluta," sino que está referida a la comunidad eclesial, a la que sirve aunque este servicio no se concrete en une comunidad local determinada. Véase al respecto: K. Rahner, art. is. (en la nota 92), pp. 378ss, 38965.

113. Quede para otro momento el reflexionar sobre el influjo que esta concepcín (unida a la visión agustiniana de la sexualidad y del pecado original) ha podido tener, de hecho, en el apartamiento de la mujer de casi toda forma de ministerio eclesial. Pero Ia vinculación entre estos factores parece imponerse intuitivamente.

114. Cita, en A Faivre, Naissance ... (cit.), p. 318.

115. Ep. XIII, 3 (PL 54, 665). Ve también la carte siguiente n.6 (PL 54, 673).

116. Cf. Ep. X, 6 (PL 54,633.634). Según mis conocimientos, le intervención total del papa en el nombramiento de los obispos no se impone plenamente hasta la epoca de Avigron. Por aquella epoca, los papas andaban muy necesitados de dinero para montar la fastuosa corte avirionense, y el obispo que era nombrado por el papa debía entregarle un aîn entero de sus rencas...

117. Cf. A. Feivre, Naissance ... (cit), p. 326.

118. Vease el canon 11: w episcopus de loco ignobili ad nobilem per ambitionem non trasseat, nec quisquan inferioris ordinis clericus. Sane, si id wilitas ecclesiae faciendum popascerit, decreto pro eo clevicorwn al laicorum episcopis prorrecto, per sentarian syodi transforatur... (Ed. Ch. Munia [P.U.F., Paris 1960], p. 81. 
119. Cf. canon 38: laicus, praesentibus clericis, nisi ipsis probantibus docere non audeat (ibid., p. 86).

120. Ut praeter eos qui sunt Domini sacerdotes, nullus sibi docendi et proedicandi ius audeat vindicare, sive ille monachus sive laicus sir, qui alicuius scientice nomine glorietwr. Quia, etsi optandwn est ut omnes Eclesiae filit quae recta et sona sunt sapiant, non tamen permistendum esf ut quisquian extra sacerdotalem ordinem constiturus, gradum sibi praedicatoris assumas, cwn in ecclesia Dei omnia ordinata esse conveniunt ut in uno Christi corpore as acellentiora membra sum officiun impleart, a inferiora superioribus non resulten (Ep. 119: PL S4,1046 A; tambitn 1040).

121. Expresiones, todas ellas, del escrito de este papa destinado a Agustín de Canterbury en el aino 601. $C f$. Cartas XI, 56 (C.C. 140 A, p. 961. En PL 77, 1215-16, con numeración diversa).

122. Cf. A. Faivre, Les laïcs .... (cit), pp. 212-217.

123. A pesar de la crítica al modo expuesta en la nota 48, tengo la impresión de que ean misma angustia se revela en el hecho, y es lo que estí en la ralz de los viajes de Juan Pablo II.

124. Todo lo eclesiástico rezuma tanto elericalismo que da cierta pena ver cómo nuestras plegarias euceristicas (ique son fruto de la reforma litưrgical), en la "oración por la Iglesia," piden detalladamente por el papa, el obispo propio (y los ajenos), el orden sacerdotal... y sólo dedican una mención global (y no siempre) al pueblo, objeto verdadero del amor de Dios y primer constitutivo de la Iglesia, como si ese puablo fiel no fuese digno de figurar demasiado al lado de tan "nobles" encomendados... Ya se que no es ésta la verdadera interpretación del hecho; pero es innegable que esta interpresación es la que más se sugiere sin querer.

125. He recogido algunos textos impresionantes de éslos úlimos en mi obra La libertad de palabra en la Iglesia y en la teologia (Sal Terrae Santander 1985). Como detalles bien expresivos de hasta dónde habla llevedo esa "cultualizeción" del ministerio, bastará con citar estos dos: los sacerdotes llamados "altaristas," que en el siglo XV se pasaban el dla diciendo misas para ganarse la vida; y el que $\rightarrow$ poco tiempo antes de las famosas tesis de Lutero sobre las indulgencias - en Findes era posible obtener Élas... como premio de la loteria.

126. El informe que Pablo II encargó a los cardenales (Contarini, Sadolet, R. Pole...) ye pedía al papa una descentralización de tantos poderes como condición para reformer la Iglesia. Pero esto no se cumplió, de la misma manera que, un siglo entes, Mutín V comerzó a separarse del concilio de Basilea cuando se le pedía que renunciara a reservarse las colaciones de beneficios. El estúpido asamblearismo eateril de este concilio le facilitó las cosas.

127. J. Comby, Para leer la historia de la Iglesia (cit en la nola 81).

128. Lo que expongo a continuación no es mio pero tempoco ha sido publicado, por la discreción de su autor. Lo he oído de él en cursos o conversaciones de seminario.

129. Cf. op. cir., pp. 111-121. 